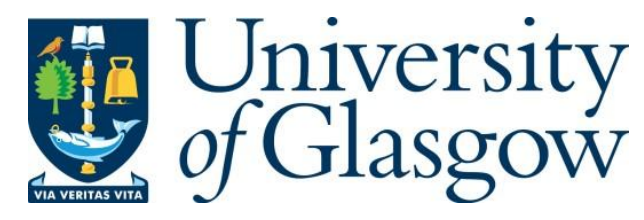

Shamsudin, M., and York, C. (2014) Mechanically coupled laminates with balanced plain weave. Composite Structures, 107 . pp. 416-428. ISSN 02638223

Copyright @ 2014 Elsevier

A copy can be downloaded for personal non-commercial research or study, without prior permission or charge

Content must not be changed in any way or reproduced in any format or medium without the formal permission of the copyright holder(s)

When referring to this work, full bibliographic details must be given

http://eprints.gla.ac.uk/84161/

Deposited on: 11 September 2013

Enlighten - Research publications by members of the University of Glasgow http://eprints.gla.ac.uk 


\title{
Mechanically Coupled Laminates with Balanced Plain
}

\section{Weave}

\author{
M H Shamsudin and C B York* \\ School of Engineering, University of Glasgow, University Avenue, G12 8QQ, Glasgow, \\ Scotland.
}

\begin{abstract}
Definitive listings of laminate stacking sequences are derived for balanced plain weave laminated materials, assuming each layer is composed of the same material with constant thickness throughout and that standard ply angle orientations 0,90 , and $\pm 45^{\circ}$ are adopted; consistent with industrial design practice. A single layer of balanced plain weave material is shown to be immune to thermal distortion following a standard high temperature manufacturing process, which implies that all laminates constructed of this material possess what is commonly referred to as the hygro-thermally curvature-stable or warp-free condition, irrespective of the individual ply orientations used or the laminate stacking sequence definition. A single uncoupled parent laminate class is shown to contain sub-groups with extensionally isotropic and fully isotropic properties that are invariant with off-axis orientation of the principal material axes with respect to the system or structural axes. By contrast a single mechanically coupled parent

\section{* Corresponding author:}

Tel: +44 (0)141 3304345, E-mail address: Christopher.York@ Glasgow.ac.uk 
laminate class is shown to give rise to seven unique forms of coupled laminate through judicious off-axis orientation. Invariant off-axis properties are also identified in coupled laminate designs. Finally, example calculations, abridged stacking sequence listings and design data are presented.

\section{Keywords}

Balanced Plain Weave, Spread Tow, Hygro-Thermally Curvature-Stable, Warp-free.

Uncoupled Laminates: Quasi-Homogeneous; Extensionally Isotropic; Fully Isotropic.

Coupled Laminates: Extension-Shearing; Extension-Bending; Extension-Twisting; Shearing-Bending; Shearing-Twisting; Bending-Twisting. 


\section{Nomenclature}
A, $\mathrm{A}_{\mathrm{ij}}=$ extensional stiffness matrix and its elements $(\mathrm{i}, \mathrm{j}=1,2,6)$.
B, $B_{i j}=$ coupling stiffness matrix and its elements $(i, j=1,2,6)$.
$\mathbf{D}, \mathrm{D}_{\mathrm{ij}} \quad=$ bending stiffness matrix and its elements $(\mathrm{i}, \mathrm{j}=1,2,6)$.
$\mathrm{E}_{1,2}, \mathrm{G}_{12}=$ in-plane Young's moduli and shear modulus.
$H \quad=$ laminate thickness (= number of plies, $n \times$ ply thickness, $t)$.
$\mathrm{M}_{\mathrm{x}, \mathrm{y}, \mathrm{xy}} \quad=$ moment resultants.
$\mathrm{N}_{\mathrm{x}, \mathrm{y}, \mathrm{xy}} \quad=$ force resultants.
$\mathbf{M}^{\text {Thermal }}=$ thermal moment resultant vector $\left(=\left\{\mathbf{M}_{\mathrm{x}}^{\text {Thermal }}, \mathbf{M}_{\mathrm{y}}^{\text {Thermal }}, \mathrm{M}_{\mathrm{xy}}{ }^{\text {Thermal }}\right\}^{\mathrm{T}}\right)$.
$\mathbf{N}^{\text {Thermal }}=$ thermal force resultant vector $\left(=\left\{\mathrm{N}_{\mathrm{x}}^{\text {Thermal }}, \mathrm{N}_{\mathrm{y}}^{\text {Thermal }}, \mathrm{N}_{\mathrm{xy}}{ }^{\text {Thermal }}\right\}^{\mathrm{T}}\right)$.
$\mathrm{Q}_{\mathrm{ij}} \quad=$ reduced stiffness $(\mathrm{i}, \mathrm{j}=1,2,6)$.
$\mathrm{U}_{\mathrm{i}} \quad=$ laminate invariant $(\mathrm{i}=1,2,3,4,5)$
$\mathrm{Z}_{\mathrm{k}}=$ layer $\mathrm{k}$ interface distance from laminate mid-plane.
$\alpha_{1,2}, \alpha_{\mathrm{Iso}}=$ principal and isotropic coefficients of thermal expansion
$\boldsymbol{\varepsilon} \quad=$ vector of in-plane strains $\left(=\left\{\varepsilon_{\mathrm{x}}, \varepsilon_{\mathrm{y}}, \varepsilon_{\mathrm{xy}}\right\}^{\mathrm{T}}\right)$.
$\boldsymbol{\kappa}=$ vector of curvatures $\left(=\left\{\kappa_{\mathrm{x}}, \kappa_{\mathrm{y}}, \kappa_{\mathrm{xy}}\right\}^{\mathrm{T}}\right)$.
$v_{\mathrm{ij}} \quad=$ Poisson ratio $(\mathrm{i}, \mathrm{j}=1,2)$
$\theta_{\mathrm{k}} \quad=$ ply orientation for layer $\mathrm{k}$
$\xi_{1-4}=$ lamination parameters for extensional stiffness.
$\xi_{5-8}=$ lamination parameters for coupling stiffness.
$\xi_{9-12}=$ lamination parameters for bending stiffness. 


\section{Introduction}

Composite laminates made from woven cloth materials are now commonplace in secondary structure applications, e.g. flight control surfaces, and are noteworthy for their improved damage tolerance compared with their unidirectional material counterparts. They are however most often used in their simplest form, i.e. balanced and symmetric laminates, to mimic the metallic materials that they are replacing, which serves only as a weight reducing strategy. Laminate tailoring using woven cloth material offers the possibility of adding additional functionality to the material, alongside weight reduction, by introducing unique mechanical interactions between inplane and out-of-plane deformations; a tailoring strategy which has been gaining increasing momentum in recent years. For instance, Nixon [1] used plain weave material to achieve mechanical Extension-Twisting coupling response in a tilt rotor blade design. This laminate design concept was first discovered by Winckler [2], who describes how Extension-Shearing coupling at the laminate level can be applied at the structural or blade level to produce an Extension-Twisting response.

Recent work on the classification of coupled laminates [3] has identified 24 distinct classes, containing all possible interactions between Extension, Shearing, Bending and Twisting. These laminate classes were derived for unidirectional material using combinations of standard fibre angle orientations, i.e. 0,90 and/or $\pm 45^{\circ}$. However, a major challenge restricting the widespread use of these mechanically coupled laminates is the complicating issue of thermal warping distortion, which occurs on cooling after the elevated temperature curing process used in the manufacture of high strength fibre- 
A single layer of plain weave material is known to possess thermal stability, i.e., immunity to thermal warping distortion. This can be understood from physical reasoning alone, where equal numbers of identical warp and weft fibres exist within a single layer, thus representing an architecture described as square symmetric [4], i.e., 
with equal stiffness on principal axes. Woven cloth architectures with square symmetric properties are generally classified as symmetric, as in plain weave, $2 \times 2$ twill weave, or $4 \times 4$ twill weave, etc. Non-symmetric woven cloth architectures, e.g. 5harness satin weave, have warp-dominated fibres on one side of the geometric midplane and weft-dominated fibres on the other. A single layer of non-symmetric woven cloth possesses coupling between in-plane and out-of-plane deformation, hence thermal warping distortions arise in such architectures [12].

Balanced plain weave architecture, illustrated in Fig. 1, can be characterized as a high crimp fabric, where the crimp angle is typically of the order of $45^{\circ}$. Micro-mechanical modelling [13-15] has helped in understanding the mechanisms leading to observed reductions in elastic properties and mechanical performance in such high crimp fabrics, compared to non-crimp fabric or unidirectional laminated material (see Table 1). However, micro-mechanical modelling is generally based on a single layer, or lamina, and on the basis of a representative volume element; multi-layer models are more realistic within the context of the current article, and have for instance demonstrated the importance of incorporating random phase shift [16] in the relative weave position between layers, but such modelling strategies quickly approach current computational limits. Indeed, present lamina level micro-mechanical modelling strategies have been shown [17] to incorrectly predict the laminate level elastic properties; the significant differences in elastic properties between a single layer and 8-layer balanced plain weave laminate have been demonstrated experimentally [18]. Indeed it has been observed that elastic modulus increases, with increasing number of layers, up to an asymptotic value corresponding to the 8-layer balanced plain weave laminate [17]. 
Straighter load-carrying fibres are present in satin and twill weave architecture, which give rise to improved mechanical performance in comparison to plain weave. However, such weave patterns violate the macro-mechanical assumption made in this study, i.e., that individual layers are specially orthotropic. Indeed, satin weave architecture has been shown [12] to lead to significant thermal warping distortions in individual layers, which is only mitigated through the use of special lamination strategies.

Spread tow, or thin ply reinforcement offers an enabling technology for enhanced mechanical performance in plain weave architecture $\left(\right.$ TeXtreme $\left.^{\circledR}\right)$, without the ply-level thermal instability of satin and twill weaves. Balanced plain weave architecture can now be achieved with crimp angles as small as $2.5^{\circ}$ by weaving flat tapes, rather than yarns, where tape widths of $20 \mathrm{~mm}$ and tape thicknesses of $70 \mu \mathrm{m}$ result in properties approaching those of non-crimp fabric.

This study is limited to the assumption of specially orthotropic layers of woven cloth material; specifically, symmetric or plain weave. Hence the classification of coupled laminates in this category may be derived from the assumption of equal modulus $\left(\mathrm{E}_{1}=\right.$ $E_{2}$ ) in the two orthogonal in-plane directions, and which can be verified experimentally (see Table 1), with the added restrictions that each layer in the laminate has identical material properties and thickness, and that layers differ only by their orientation.

The governing equations describing the physical behaviour and specific characteristics of balanced plain weave laminates are developed in section 2. Section 3 highlights special stiffness relationships for both uncoupled and coupled laminates with balanced plain weave and summarises the number of laminate solutions with standard ply angles. Comparisons for Extension-Twisting coupled laminate designs with unidirectional and balanced plain weave materials are presented in section 4 before conclusions are drawn 
in section 5. Finally, an appendix is provided, containing: a summary of laminate characterisation and; abridged stacking sequence listings with design parameters for uncoupled and coupled laminates with balanced plain weave architecture.

\section{Laminate Characterisation}

Coupled laminates may be classified by either a suitable description of the form of the ABD stiffness matrix, i.e.:

$$
\begin{aligned}
& \left\{\begin{array}{c}
\mathrm{N}_{\mathrm{x}}+\mathrm{N}_{\mathrm{x}}^{\text {Thermal }} \\
\mathrm{N}_{\mathrm{y}}+\mathrm{N}_{\mathrm{y}}^{\text {Thermal }} \\
\mathrm{N}_{\mathrm{xy}}+\mathrm{N}_{\mathrm{xy}}^{\text {Thermal }}
\end{array}\right\}=\left[\begin{array}{lll}
\mathrm{A}_{11} & \mathrm{~A}_{12} & \mathrm{~A}_{16} \\
\mathrm{~A}_{12} & \mathrm{~A}_{22} & \mathrm{~A}_{26} \\
\mathrm{~A}_{16} & \mathrm{~A}_{26} & \mathrm{~A}_{66}
\end{array}\right]\left\{\begin{array}{c}
\varepsilon_{\mathrm{x}} \\
\varepsilon_{\mathrm{y}} \\
\gamma_{\mathrm{xy}}
\end{array}\right\}+\left[\begin{array}{lll}
\mathrm{B}_{11} & \mathrm{~B}_{12} & \mathrm{~B}_{16} \\
\mathrm{~B}_{12} & \mathrm{~B}_{22} & \mathrm{~B}_{26} \\
\mathrm{~B}_{16} & \mathrm{~B}_{26} & \mathrm{~B}_{66}
\end{array}\right]\left\{\begin{array}{c}
\kappa_{\mathrm{x}} \\
\kappa_{\mathrm{y}} \\
\kappa_{\mathrm{xy}}
\end{array}\right\} \\
& \left\{\begin{array}{c}
\mathrm{M}_{\mathrm{x}}+\mathrm{M}_{\mathrm{x}}^{\text {Thermal }} \\
\mathrm{M}_{\mathrm{y}}+\mathrm{M}_{\mathrm{y}}^{\text {Thermal }} \\
\mathrm{M}_{\mathrm{xy}}+\mathrm{M}_{\mathrm{xy}}^{\text {Thermal }}
\end{array}\right\}=\left[\begin{array}{lll}
\mathrm{B}_{11} & \mathrm{~B}_{12} & \mathrm{~B}_{16} \\
\mathrm{~B}_{12} & \mathrm{~B}_{22} & \mathrm{~B}_{26} \\
\mathrm{~B}_{16} & \mathrm{~B}_{26} & \mathrm{~B}_{66}
\end{array}\right]\left\{\begin{array}{c}
\varepsilon_{\mathrm{x}} \\
\varepsilon_{\mathrm{y}} \\
\gamma_{\mathrm{xy}}
\end{array}\right\}+\left[\begin{array}{lll}
\mathrm{D}_{11} & \mathrm{D}_{12} & \mathrm{D}_{16} \\
\mathrm{D}_{12} & \mathrm{D}_{22} & \mathrm{D}_{26} \\
\mathrm{D}_{16} & \mathrm{D}_{26} & \mathrm{D}_{66}
\end{array}\right]\left\{\begin{array}{c}
\kappa_{\mathrm{x}} \\
\kappa_{\mathrm{y}} \\
\kappa_{\mathrm{xy}}
\end{array}\right\}
\end{aligned}
$$

or, by a description of the physical response, due to an applied set of force and/or moment resultants. The two classifications are complementary and are therefore both employed here to provide additional insight. In the first case, the Engineering Sciences Data Unit [19] subscript notation is used, with suitable augmentation, to describe the exact form of the elements in the extensional $[\mathbf{A}]$, coupling $[\mathbf{B}]$, and bending $[\mathbf{D}]$ stiffness matrices, which in turn relate to the precise form of coupling behaviour of the laminate. In the second case, a cause-effect response based labelling system is adopted [3]. Detailed comparisons of both systems are provided in the appendix (Table A1). 
The elements of the ABD matrix in Eq. (1) can be calculated from the (independent) laminate invariants, $\mathrm{U}_{\mathrm{i}}(\mathrm{i}=1, \ldots, 5)$, and lamination parameters, $\xi_{\mathrm{j}}(\mathrm{j}=1, \ldots, 12)$ :
$\mathrm{A}_{11}=\left(\mathrm{U}_{1}+\xi_{1} \mathrm{U}_{2}+\xi_{2} \mathrm{U}_{3}\right) H$
$\mathrm{B}_{11}=\left(\xi_{5} \mathrm{U}_{2}+\xi_{6} \mathrm{U}_{3}\right) H^{2} / 4$
$\mathrm{D}_{11}=\left(\mathrm{U}_{1}+\xi_{9} \mathrm{U}_{2}+\xi_{10} \mathrm{U}_{3}\right) H^{3} / 12$
$\mathrm{A}_{12}=\mathrm{A}_{21}=\left(-\xi_{2} \mathrm{U}_{3}+\mathrm{U}_{4}\right) H$
$\mathrm{B}_{12}=\mathrm{B}_{21}=\left(-\xi_{6} \mathrm{U}_{3}\right) H^{2} / 4$
$\mathrm{D}_{12}=\mathrm{D}_{21}=\left(\mathrm{U}_{4}-\xi_{10} \mathrm{U}_{3}\right) H^{3} / 12$
$\mathrm{A}_{16}=\mathrm{A}_{61}=\left(\xi_{3} \mathrm{U}_{2} / 2+\xi_{4} \mathrm{U}_{3}\right) H$
$\mathrm{B}_{16}=\mathrm{B}_{61}=\left(\xi_{7} \mathrm{U}_{2} / 2+\xi_{8} \mathrm{U}_{3}\right) H^{2} / 4$
$\mathrm{D}_{16}=\mathrm{D}_{61}=\left(\xi_{11} \mathrm{U}_{2} / 2+\xi_{12} \mathrm{U}_{3}\right) H^{3} / 12$
$\mathrm{A}_{22}=\left(\mathrm{U}_{1}-\xi_{1} \mathrm{U}_{2}+\xi_{2} \mathrm{U}_{3}\right) H$
$\mathrm{B}_{22}=\left(-\xi_{5} \mathrm{U}_{2}+\xi_{6} \mathrm{U}_{3}\right) H^{2} / 4$
$\mathrm{D}_{22}=\left(\mathrm{U}_{1}-\xi_{9} \mathrm{U}_{2}+\xi_{10} \mathrm{U}_{3}\right) H^{3} / 12$
$\mathrm{A}_{26}=\mathrm{A}_{62}=\left(\xi_{3} \mathrm{U}_{2} / 2-\xi_{4} \mathrm{U}_{3}\right) H$
$\mathrm{B}_{26}=\mathrm{B}_{62}=\left(\xi_{7} \mathrm{U}_{2} / 2-\xi_{8} \mathrm{U}_{3}\right) H^{2} / 4$
$\mathrm{D}_{26}=\mathrm{D}_{62}=\left(\xi_{11} \mathrm{U}_{2} / 2-\xi_{12} \mathrm{U}_{3}\right) H^{3} / 12$
$\mathrm{A}_{66}=\left(-\xi_{2} \mathrm{U}_{3}+\mathrm{U}_{5}\right) H$
$\mathrm{B}_{66}=\left(-\xi_{6} \mathrm{U}_{3}\right) H^{2} / 4$
$\mathrm{D}_{66}=\left(-\xi_{10} \mathrm{U}_{3}+\mathrm{U}_{5}\right) H^{3} / 12$

The thermal force and moment vectors also involve the thermal coefficients, $\alpha_{1}$ and $\alpha_{2}$ :

$$
\begin{aligned}
& \left\{\begin{array}{l}
\mathrm{N}_{\mathrm{x}}^{\text {Thermal }} \\
\mathrm{N}_{\mathrm{y}}^{\text {Thermal }} \\
\mathrm{N}_{\mathrm{xy}}^{\text {Thermal }}
\end{array}\right\}=\frac{H}{2}\left\{\begin{array}{c}
\left(\mathrm{U}_{1}+\mathrm{U}_{4}\right)\left(\alpha_{1}+\alpha_{2}\right)+\mathrm{U}_{2}\left(\alpha_{1}-\alpha_{2}\right)+\xi_{1}\left[\mathrm{U}_{2}\left(\alpha_{1}+\alpha_{2}\right)+\left(\mathrm{U}_{1}+2 \mathrm{U}_{3}-\mathrm{U}_{4}\right)\left(\alpha_{1}-\alpha_{2}\right)\right] \\
\left(\mathrm{U}_{1}+\mathrm{U}_{4}\right)\left(\alpha_{1}+\alpha_{2}\right)+\mathrm{U}_{2}\left(\alpha_{1}-\alpha_{2}\right)-\xi_{1}\left[\mathrm{U}_{2}\left(\alpha_{1}+\alpha_{2}\right)+\left(\mathrm{U}_{1}+2 \mathrm{U}_{3}-\mathrm{U}_{4}\right)\left(\alpha_{1}-\alpha_{2}\right)\right] \\
\xi_{3}\left[\mathrm{U}_{2}\left(\alpha_{1}+\alpha_{2}\right)+\left(\mathrm{U}_{1}+2 \mathrm{U}_{3}-\mathrm{U}_{4}\right)\left(\alpha_{1}-\alpha_{2}\right)\right]
\end{array}\right\} \Delta \mathrm{T} \\
& \left\{\begin{array}{l}
\mathrm{M}_{\mathrm{x}}^{\text {Thermal }} \\
\mathrm{M}_{\mathrm{y}}^{\text {Thermal }} \\
\mathrm{M}_{\mathrm{xy}}^{\text {Thermal }}
\end{array}\right\}=\frac{H^{2}}{8}\left\{\begin{array}{c}
\xi_{5}\left[\mathrm{U}_{2}\left(\alpha_{1}+\alpha_{2}\right)+\left(\mathrm{U}_{1}+2 \mathrm{U}_{2}-\mathrm{U}_{4}\right)\left(\alpha_{1}-\alpha_{2}\right)\right] \\
-\xi_{5}\left[\mathrm{U}_{2}\left(\alpha_{1}+\alpha_{2}\right)+\left(\mathrm{U}_{1}+2 \mathrm{U}_{3}-\mathrm{U}_{4}\right)\left(\alpha_{1}-\alpha_{2}\right)\right] \\
\xi_{7}\left[\mathrm{U}_{2}\left(\alpha_{1}+\alpha_{2}\right)+\left(\mathrm{U}_{1}+2 \mathrm{U}_{2}-\mathrm{U}_{4}\right)\left(\alpha_{1}-\alpha_{2}\right)\right]
\end{array}\right\} \Delta \mathrm{T}
\end{aligned}
$$

where the laminate invariants, $\mathrm{U}_{\mathrm{i}}$, are defined as:

$$
\begin{array}{ll}
\mathrm{U}_{1}=\frac{\left(3 \mathrm{Q}_{11}+3 \mathrm{Q}_{22}+2 \mathrm{Q}_{12}+4 \mathrm{Q}_{66}\right)}{8} & \mathrm{U}_{2}=\frac{\left(\mathrm{Q}_{11}-\mathrm{Q}_{22}\right)}{2} \\
\mathrm{U}_{4}=\frac{\left(\mathrm{Q}_{11}+\mathrm{Q}_{22}+6 \mathrm{Q}_{12}-4 \mathrm{Q}_{66}\right)}{8} & \mathrm{U}_{5}=\frac{\left(\mathrm{Q}_{11}+\mathrm{Q}_{22}-2 \mathrm{Q}_{12}+4 \mathrm{Q}_{66}\right)}{8}
\end{array}
$$

and lamination parameters, $\xi_{\mathrm{j}}$, are defined in condensed form as: 


$$
\begin{aligned}
& \xi_{1}, \xi_{2}, \xi_{3}, \xi_{4}=\frac{1}{n} \sum_{\mathrm{k}=1}^{\mathrm{n}}\left(\mathrm{z}_{\mathrm{k}}-\mathrm{z}_{\mathrm{k}-1}\right)\left(\cos 2 \theta_{\mathrm{k}}, \cos 4 \theta_{\mathrm{k}}, \sin 2 \theta_{\mathrm{k}}, \sin 4 \theta_{\mathrm{k}}\right) \\
& \xi_{5}, \xi_{6}, \xi_{7}, \xi_{8}=\frac{2}{n^{2}} \sum_{\mathrm{k}=1}^{\mathrm{n}}\left(\mathrm{z}_{\mathrm{k}}^{2}-\mathrm{z}_{\mathrm{k}-1}^{2}\right)\left(\cos 2 \theta_{\mathrm{k}}, \cos 4 \theta_{\mathrm{k}}, \sin 2 \theta_{\mathrm{k}}, \sin 4 \theta_{\mathrm{k}}\right) \\
& \xi_{9}, \xi_{10}, \xi_{11}, \xi_{12}=\frac{4}{n^{3}} \sum_{\mathrm{k}=1}^{\mathrm{n}}\left(\mathrm{z}_{\mathrm{k}}^{3}-\mathrm{z}_{\mathrm{k}-1}^{3}\right)\left(\cos 2 \theta_{\mathrm{k}}, \cos 4 \theta_{\mathrm{k}}, \sin 2 \theta_{\mathrm{k}}, \sin 4 \theta_{\mathrm{k}}\right)
\end{aligned}
$$

with the implied convention that each comma separated lamination parameter on the left-hand side of the equation relates to the corresponding trigonometric term on the right-hand side.

Finally, the reduced stiffness terms, $\mathrm{Q}_{\mathrm{ij}}$, are calculated from the engineering properties:

$$
\mathrm{Q}_{11}=\mathrm{E}_{1} /\left(1-v_{12} v_{21}\right), \mathrm{Q}_{12}=v_{12} \mathrm{E}_{2} /\left(1-v_{12} v_{21}\right), \mathrm{Q}_{22}=\mathrm{E}_{2} /\left(1-v_{12} v_{21}\right), \mathrm{Q}_{66}=\mathrm{G}_{12}
$$

Due to the balanced nature of a single layer of plain weave, i.e., equal fibre volume fractions in the 0 and $90^{\circ}$ directions, see Fig. 1, the warp and weft directions are indistinguishable, thus justifying the equal modulus $\left(\mathrm{E}_{1}=\mathrm{E}_{2}\right)$ condition assumed. Hence, standard ply angle orientations, 0,90 and $\pm 45^{\circ}$, simplify to 0 and $45^{\circ}$; since the orthogonal counterparts, 90 and $-45^{\circ}$, possess exactly the same properties, respectively. In addition, the laminate invariant $\mathrm{U}_{2}=0$, since $\mathrm{Q}_{11}=\mathrm{Q}_{22}$ follows directly from the equal modulus assumption. The thermal coefficients $\alpha_{1}=\alpha_{2}=\alpha_{\text {Iso }}$ follow from the same physical reasoning, and are also readily demonstrated from $\alpha_{\text {Iso }}$ for the equivalent isotropic laminate and the reduced form for balanced plain weave, i.e.:

$$
\begin{aligned}
& \alpha_{\text {iso }}=\frac{\alpha_{1}+\alpha_{2}}{2}+\frac{\left(\alpha_{1}-\alpha_{2}\right) U_{2}}{2\left(U_{1}+2 U_{4}\right)} \\
& \alpha_{\text {iso }}=\frac{\alpha_{1}+\alpha_{2}}{2}
\end{aligned}
$$


Note that mechanical isotropy also leads to thermal isotropy but the reverse is not necessarily true, i.e., thermal isotropy does not guarantee mechanical isotropy.

As a result of these simplifications, the elements of the ABD matrix in Eq. (1) simplify compared to those for laminates containing layers of unidirectional material, giving:

$$
\begin{array}{lll}
\mathrm{A}_{11}=\left(\mathrm{U}_{1}+\xi_{2} \mathrm{U}_{3}\right) H & \mathrm{~B}_{11}=\left(\xi_{6} \mathrm{U}_{3}\right) H^{2} / 4 & \mathrm{D}_{11}=\left(\mathrm{U}_{1}+\xi_{10} \mathrm{U}_{3}\right) H^{3} / 12 \\
\mathrm{~A}_{12}=\mathrm{A}_{21}=\left(-\xi_{2} \mathrm{U}_{3}+\mathrm{U}_{4}\right) H & \mathrm{~B}_{12}=\mathrm{B}_{21}=\left(-\xi_{6} \mathrm{U}_{3}\right) H^{2} / 4 & \mathrm{D}_{12}=\mathrm{D}_{21}=\left(\mathrm{U}_{4}-\xi_{10} \mathrm{U}_{3}\right) H^{3} / 12 \\
\mathrm{~A}_{16}=\mathrm{A}_{61}=\left(\xi_{4} \mathrm{U}_{3}\right) H & \mathrm{~B}_{16}=\mathrm{B}_{61}=\left(\xi_{8} \mathrm{U}_{3}\right) H^{2} / 4 & \mathrm{D}_{16}=\mathrm{D}_{61}=\left(\xi_{12} \mathrm{U}_{3}\right) H^{3} / 12 \\
\mathrm{~A}_{22}=\left(\mathrm{U}_{1}+\xi_{2} \mathrm{U}_{3}\right) H & \mathrm{~B}_{22}=\left(\xi_{6} \mathrm{U}_{3}\right) H^{2} / 4 & \mathrm{D}_{22}=\left(\mathrm{U}_{1}+\xi_{10} \mathrm{U}_{3}\right) H^{3} / 12 \\
\mathrm{~A}_{26}=\mathrm{A}_{62}=\left(-\xi_{4} \mathrm{U}_{3}\right) H & \mathrm{~B}_{26}=\mathrm{B}_{62}=\left(-\xi_{8} \mathrm{U}_{3}\right) H^{2} / 4 & \mathrm{D}_{26}=\mathrm{D}_{62}=\left(-\xi_{12} \mathrm{U}_{3}\right) H^{3} / 12 \\
\mathrm{~A}_{66}=\left(-\xi_{2} \mathrm{U}_{3}+\mathrm{U}_{5}\right) H & \mathrm{~B}_{66}=\left(-\xi_{6} \mathrm{U}_{3}\right) H^{2} / 4 & \mathrm{D}_{66}=\left(-\xi_{10} \mathrm{U}_{3}+\mathrm{U}_{5}\right) H^{3} / 12
\end{array}
$$

$$
\left\{\begin{array}{l}
\mathbf{M}_{\mathrm{x}}^{\text {Thermal }} \\
\mathbf{M}_{\mathrm{y}}^{\text {Thermal }} \\
\mathbf{M}_{\mathrm{xy}}^{\text {Thermal }}
\end{array}\right\}=\left\{\begin{array}{l}
0 \\
0 \\
0
\end{array}\right\}
$$

involving a reduced set of laminate invariants, $\mathrm{U}_{\mathrm{i}}$ :

$$
\begin{array}{ll}
\mathrm{U}_{1}=\frac{\left(6 \mathrm{Q}_{11}+2 \mathrm{Q}_{12}+4 \mathrm{Q}_{66}\right)}{8} & \mathrm{U}_{3}=\frac{\left(2 \mathrm{Q}_{11}-2 \mathrm{Q}_{12}-4 \mathrm{Q}_{66}\right)}{8} \\
\mathrm{U}_{4}=\frac{\left(2 \mathrm{Q}_{11}+6 \mathrm{Q}_{12}-4 \mathrm{Q}_{66}\right)}{8} & \mathrm{U}_{5}=\frac{\left(2 \mathrm{Q}_{11}-2 \mathrm{Q}_{12}+4 \mathrm{Q}_{66}\right)}{8}
\end{array}
$$

and consequently a reduced set of lamination parameter constraints: 


$$
\xi_{2}, \xi_{4}=\frac{1}{n} \sum_{\mathrm{k}=1}^{\mathrm{n}}\left(\mathrm{z}_{\mathrm{k}}-\mathrm{z}_{\mathrm{k}-1}\right)\left(\cos 4 \theta_{\mathrm{k}}, \sin 4 \theta_{\mathrm{k}}\right)
$$$$
\xi_{6}, \xi_{8}=\frac{2}{n^{2}} \sum_{\mathrm{k}=1}^{\mathrm{n}}\left(\mathrm{z}_{\mathrm{k}}^{2}-\mathrm{z}_{\mathrm{k}-1}^{2}\right)\left(\cos 4 \theta_{\mathrm{k}}, \sin 4 \theta_{\mathrm{k}}\right)
$$$$
\xi_{10}, \xi_{12}=\frac{4}{n^{3}} \sum_{\mathrm{k}=1}^{\mathrm{n}}\left(\mathrm{z}_{\mathrm{k}}^{3}-\mathrm{z}_{\mathrm{k}-1}^{3}\right)\left(\cos 4 \theta_{\mathrm{k}}, \sin 4 \theta_{\mathrm{k}}\right)
$$

Additionally, for axis-aligned laminates, i.e. where the principal material axis is coincident with the system or structural axis, the lamination parameters $\xi_{4}, \xi_{8}$, and $\xi_{12}$ are zero for standard ply angle orientations $\left(0\right.$ and $\left.45^{\circ}\right)$, and correspond to $\mathrm{A}_{16}=\mathrm{A}_{26}=$ $0, \mathrm{~B}_{16}=\mathrm{B}_{26}=0$ and $\mathrm{D}_{16}=\mathrm{D}_{26}=0$, respectively.

Different forms of the ABD matrix arise from off-axis alignment, $\beta$, of the principal material axis with respect to the system or structural axis for unidirection and plain weave materials. The square symmetric forms giving rise to HTCS laminates are summarized in Tables 2 and 3.

The square symmetric form of each of these matrices, which is common to all balanced plain weave laminates, implies that the general form remains unchanged, but because the magnitude of the terms vary sinusoidally, specific off-axis rotations, $\beta$, render certain coupling terms zero. This unique feature can therefore be exploited to tailor the mechanical coupling properties, without affecting the immunity to thermal warping distortions.

Table 2 demonstrates these relationships for the extensional [A] and bending [D] stiffness properties, which are uncoupled when the principal material axes are orthogonal to the system or structural axes, but are coupled in Extension-Shearing $(\underline{E-S})$ 
serves to demonstrates the validity of the cause-effect relationships, based on the form of the stiffness matrix, rather than compliance matrix, not only as a general descriptor of the laminate coupling behaviour, but also for assessing the presence of any secondary couplings without the requirement for matrix inversion.

Isotropy in the thermal force vector of Eq. (8), a zero thermal moment vector, and square symmetry in the extensional $[\mathbf{A}]$ and coupling $[\mathbf{B}]$ stiffness matrices are the necessary conditions for HTCS laminates [10,11]. The equal principal strains that result from the isotropic thermal force vector imply that the Mohr's circle for strain transformations degenerates to a point (in the same way that Mohr's circle for stress degenerates to a point under a hydrostatic stress state), hence thermal strains are identical in all directions and therefore plies of any orientation may be laminated together without warping following post-cure cool-down.

It is worth noting that the bending [D] stiffness matrix is square symmetric for all balanced plain weave laminates, but this is not a necessary condition for HTCS laminates, as demonstrate elsewhere [10] for laminates consisting of unidirectional material.

In fact only two parent classes exist for laminates with balanced plain weave and standard ply angle orientations: the Simple $\left(\mathbf{A}_{S} \mathbf{B}_{0} \mathbf{D}_{\mathrm{S}}\right)$ laminate and; the ExtensionBending and Shearing-Twisting $(\underline{E-B}-\underline{S-T})$ coupled $\left(\mathbf{A}_{\mathrm{S}} \mathbf{B}_{\mathrm{S}} \mathbf{D}_{\mathrm{S}}\right)$ laminate. All other mechanical coupling responses arise from off-axis orientation, $\beta$, of the principal material axes of these parent laminates, with respect to the system or structural axes. 


\section{Results and Discussion}

\subsection{Uncoupled Laminates with Balanced Plain Weave}

The most commonly adopted method for achieving fully uncoupled laminates is through the use of balanced and symmetric construction. However, non-symmetric laminate configurations are now known to dominate the design space of Simple (uncoupled) laminates. The Simple $\left(\mathbf{A}_{S} \mathbf{B}_{0} \mathbf{D}_{S}\right)$ laminate is identified from solutions with lamination parameters:

$\xi_{6}=\xi_{8}=0$

where $\xi_{8}=0$ due to the standard ply angle orientations adopted.

A sub-group of fully isotropic $\left(\mathbf{A}_{\mathrm{I}} \mathbf{B}_{0} \mathbf{D}_{\mathrm{I}}\right)$ laminates also exist from within the Simple $\left(\mathbf{A}_{\mathrm{S}} \mathbf{B}_{0} \mathbf{D}_{\mathrm{S}}\right)$ laminate class, and can be identified through the additional lamination parameter constraints:

$\xi_{2}=\xi_{4}=\xi_{10}=\xi_{12}=0$

from which Eq. (8) reveals that the extensional $[\mathbf{A}]$ and bending [D] stiffness matrices depend solely on the laminate invariants, $U_{i}$, i.e. the material properties. Here, the extensional stiffnesses:

$\mathrm{A}_{11}=\mathrm{A}_{22}$ and $\mathrm{A}_{66}=\left(\mathrm{A}_{11}-\mathrm{A}_{12}\right) / 2$

are concomitant with the bending stiffnesses, i.e.:

$\mathrm{D}_{\mathrm{ij}}=\mathrm{A}_{\mathrm{ij}} H^{2} / 12$

which together correspond to the fully isotropic condition. 
The polar plots of Fig. 2 demonstrate the lamination parameter and extensional stiffness variations for a single layer of balanced plain weave fabric with off-axis orientation $0^{\circ} \leq$ $\beta \leq 360^{\circ}$. The more common form, demonstrating effective moduli, is also presented. Note that Eq. (15) applies in the single layer case, hence $\xi_{10}=\xi_{2}$ and $\xi_{12}=\xi_{4}$.

Vincenti et al. [21] adopted the polar method, developed by Verchery [22], to investigate specific properties of uncoupled balanced plain weave laminates. Some interesting solutions were given demonstrating that the square symmetric concomitant properties in extension and bending can also be tailored, through the use of nonstandard ply angle orientations, so that the alignment of principal extensional stiffness is different to the principal bending stiffness. By contrast, Grediac [23] found approximate solutions with extensional isotropy and fully isotropic properties, for laminates with up to 11 plies, by solving the lamination parameter constraints using an optimisation strategy with free form ply angle orientations. The single, exact solution, found for an 8-ply fully isotropic laminate, with standard ply angle orientations, is reconfirmed in this article together with exact solutions for higher ply number groupings.

The number of solutions for Simple $\left(\mathbf{A}_{S} \mathbf{B}_{0} \mathbf{D}_{S}\right)$ laminates is presented in Table 5 for each ply number grouping with up to 21 plies. These Simple laminates also contain subgroups with quasi-homogeneous $\left(\mathbf{A}_{S} \mathbf{B}_{0} \mathbf{D}_{\mathrm{S}}\right)$ and fully isotropic $\left(\mathbf{A}_{\mathrm{I}} \mathbf{B}_{0} \mathbf{D}_{\mathrm{I}}\right)$ properties, both satisfying Eq. (15), and extensionally isotropic $\left(\mathbf{A}_{I} \mathbf{B}_{0} \mathbf{D}_{\mathrm{S}}\right)$ properties, all of which are quantified in Table 5. Where single quasi-homogeneous solutions are reported for particular ply number groupings, the form of the stacking sequence is represented by $[\alpha]_{\mathrm{rT}}$, where the number of repetitions, $r$, corresponds to the number of plies, $n$; all share the same non-dimensional properties as the single ply, shown in Fig. 2. 
An abridged listing of stacking sequences for Simple $\left(\mathbf{A}_{S} \mathbf{B}_{0} \mathbf{D}_{S}\right)$ laminates with up to 21 plies is presented in the appendix (Table A2); these are ordered by increasing compression buckling strength, corresponding to the infinitely long plate with simply supported edges, for which the closed form solution of Eq. (16) is applicable. The complete list of stacking sequences for fully isotropic laminates with up to 21 plies is presented in Table 6.

\subsection{Coupled Laminates with Balanced Plain Weave}

The coupled parent $\left(\mathbf{A}_{S} \mathbf{B}_{S} \mathbf{D}_{\mathrm{S}}\right)$ laminate class possesses Extension-Bending and Shearing-Twisting $(\underline{E-B}-\underline{S-T})$ coupling, which corresponds to the lamination parameter constraint:

$\xi_{6} \neq 0$

Additional coupling characteristics can be obtained from this parent laminate class by applying off-axis material alignment, $\beta$.

Note that the HTCS condition, present in a single layer of balanced plain weave material is retained for general off-axis material alignment, $\beta$. This extends to all plain weave laminates, irrespective of the number of plies in the laminate or the laminate stacking sequence. By contrast, fibre misalignment errors in the stacking sequences for HTCS laminates with unidirectional material, or unbalanced plain weave, will inevitably give rise to some degree of thermal warping. Additionally, HTCS laminates with unidirectional material are achievable only for certain ply number groupings when standard ply angle orientations are adopted [10], i.e., with 8, 12, 16 and 20 plies, etc. It has however recently been shown [24] that HTCS solutions can be achieved in all ply 
number groupings with 10 plies and above if non-standard ply orientations are adopted, i.e., $\theta=0,90$ and $\pm 60^{\circ}$.

Seven classes of coupled laminate can be produced from balanced plain weave material. All are derived from the single parent $\left(\mathbf{A}_{S} \mathbf{B}_{S} \mathbf{D}_{\mathrm{S}}\right)$ laminate class, through the off-axis alignments detailed in Tables 2 and 3. The 6 derivatives are summarized in Table 7 . In addition, a sub-group of these coupled laminates have been discovered with both extensional and bending stiffness isotropy; solutions which also possess compliance isotropy. Illustrations in Table 7 represent unconstrained thermal contraction responses that would typically result at room temperature, following a standard high temperature curing process. They provide classical laminate theory predictions of the warping behaviour that is avoided in balanced plain weave laminates, by virtue of their HTCS properties, for all 7 classes of mechanical coupling. Note that the stacking sequences given are representative samples from the minimum ply number grouping for each class of coupled laminate; given as the parent laminate, with standard ply angle orientations, prior to off-axis material alignment, $\beta$, where $\alpha=\beta+\pi / 4$.

The number of solutions in each of the 7 coupled laminate classes are listed in Table 8. The second column of the table represents the number of Extension-Bending and Shearing-Twisting $(\underline{E-B}-\underline{S-T})$ parent $\left(\mathbf{A}_{S} \mathbf{B}_{S} \mathbf{D}_{\mathrm{S}}\right)$ laminate solutions for each ply number grouping, $n$. Subsequent columns demonstrate the number of solutions in each coupled laminate derivative arising from a specific off-axis orientation, $\beta$. The results reveal that the two parent solutions for the 2-ply laminate $(n=2)$ give rise to either the $\mathbf{A}_{\mathrm{S}} \mathbf{B}_{t} \mathbf{D}_{\mathrm{S}}$ or the $\mathbf{A}_{S} \mathbf{B}_{\mathrm{F}} \mathbf{D}_{\mathrm{S}}$ coupled laminate classes following off-axis rotation. Both solutions are fully isotropic in Extension [A] and Bending [D] and therefore an off-axis rotation changes only the Coupling [B] matrix properties. For instance, off-axis material 
Finally, the 28 solutions for 6 -ply laminates $(n=6)$, presented in Table 8 result in all six mechanically coupled classes as a result of off-axis orientation, $\beta$. Figure 5 illustrates the polar plots of lamination parameter relationships for the 6-ply stacking sequence $\left[\alpha / \beta / \alpha_{2} / \beta_{2}\right]_{\mathrm{T}}$. In this case the lamination parameters $\xi_{2}=\xi_{4}=0$ for all axis alignments, indicating that this laminate possesses isotropic extensional [A] stiffness properties. However, this is not a true isotropy condition since it not reflected in the compliance relationship, where the isotropy is lost as a result of the influence of Bending-Twisting coupling through the Coupling [B] matrix. Once again the Coupling [B] stiffness matrix properties are similar to the previous examples, albeit with different magnitude. Bending-Twisting coupling is present at all off-axis orientations, since $\xi_{12}=0$ only for $\beta$ $=m \pi / 4(m=0,1,2, \ldots)$. This example represents the $\mathbf{A}_{S} \mathbf{B}_{t} \mathbf{D}_{\mathrm{F}}$ and $\mathbf{A}_{\mathrm{S}} \mathbf{B}_{\mathrm{F}} \mathbf{D}_{\mathrm{F}}$ laminate classes in Table 7, depending on the specific off-axis orientation, $\beta$.

\section{Laminate Design}

This section presents two worked examples, the first of which is a comparison of unidirectional and balanced plain weave laminates for a rotor blade application in which maximum twist, through mechanical extension-twisting coupling, is required under a given centrifugal loading condition. The stacking sequences chosen have the highest coupling magnitude achievable using standard ply angle orientations, i.e. 0,90 and $\pm 45^{\circ}$. It should be noted however that whilst standard ply orientations were chosen to satisfy manufacturing constraints, the laminates are assumed to be loaded off-axis, in order to induce extension-twisting coupling. The stacking sequence chosen to represent the balanced plain weave laminate, $\left[\alpha_{2} / \beta_{2}\right]_{\mathrm{T}}$, therefore corresponds to $\left[67.5_{2} / 22.5_{2}\right]_{\mathrm{T}}$ in accordance with the design rules of Table 3 , i.e., an off-axis orientation, $\beta=\pi / 8$. The 
competing unidirectional laminate of equal thickness, whose stacking sequence has been derived independently by others $[1,9,10]$, corresponds to $\left[-22.5 / 67.5_{2} /-22.5 / 22.5 /-\right.$ $\left.67.52_{2} / 22.5\right]_{\mathrm{T}}$, following off-axis orientation.

The reduced stiffnesses are readily calculated from the material properties of Table 1 using Eq. (6), giving $\mathrm{Q}_{11}=\mathrm{Q}_{22}=90,226, \mathrm{Q}_{12}=4,511$ and $\mathrm{Q}_{66}=5,000\left(\mathrm{~N} / \mathrm{mm}^{2}\right)$ for balanced plain weave material. The laminate invariants $U_{1}=71,297, U_{3}=18,929, U_{4}=$ 23,440 and $\mathrm{U}_{5}=23,929\left(\mathrm{~N} / \mathrm{mm}^{2}\right)$ follow from Eq. (10) and the only non-zero lamination parameter, obtained from Eq. (11), is $\xi_{8}=1$. The elements of the ABD matrix then follow from Eq. (8), giving:

$\left[\begin{array}{cccccc}104,379 & 34,316 & 0 & 0 & 0 & 10,142 \\ 34,316 & 104,379 & 0 & 0 & 0 & -10,142 \\ 0 & 0 & 35,031 & 10,142 & -10,142 & 0 \\ 0 & 0 & 10,142 & 18,643 & 6,129 & 0 \\ 0 & 0 & -10,142 & 6,129 & 18,643 & 0 \\ 10,142 & -10,142 & 0 & 0 & 0 & 6,257\end{array}\right]$

For the unidirectional material comparator, the reduced stiffnesses also follow from Table 1, using Eq. (6), but now the laminate invariants follow from Eq. (4), the two non-zero lamination parameters, $\xi_{8}=1$ and $\xi_{9}=0.133$, follow from Eq. (5) and the elements of the ABD matrix follow from Eq. (2), giving:

$\left[\begin{array}{cccccc}102,765 & 32,342 & 0 & 0 & 0 & 10,530 \\ 32,342 & 102,765 & 0 & 0 & 0 & -10,530 \\ 0 & 0 & 35,212 & 10,530 & -10,530 & 0 \\ 0 & 0 & 10,530 & 21,156 & 5,776 & 0 \\ 0 & 0 & -10,530 & 5,776 & 21,156 & 0 \\ 10,530 & -10,530 & 0 & 0 & 0 & 6,289\end{array}\right]$


The predicted failure loads under uniaxial tension, derived using the inverse of Eq. (1), see Table 4, are $10.72 \mathrm{kN}$ and $9.42 \mathrm{kN}$ for the unidirectional and balanced plain weave materials, respectively. However, the finite element analyses predict failure loads of $11.45 \mathrm{kN}$ and $10.10 \mathrm{kN}$, due to the applied boundary conditions, which simulate the tension grips of a tension-torsion test machine. 
This example demonstrates that the design constraint of square symmetry in the $\mathbf{A}$ and B stiffness matrices, necessary to avoid thermal warping distortion in coupled laminates, has the effect of reducing the advantages of unidirectional material over balanced plain weave material.

A second example compares the compression buckling strength for unidirectional and balanced plain weave, using the same stacking sequences. Note that the elements of the ABD matrix in Eqs (17) and (18) must first be recalculated using the compressive moduli of Table 1. The Tsai-Wu failure criterion failure loads under uniaxial compression, derived using the inverse of Eq. (1), are now $12.83 \mathrm{kN}$ and $8.76 \mathrm{kN}$, respectively.

The buckling strength of Extension-Twisting (and Shearing-Bending) coupled laminates can be calculated from a closed form buckling solution:

$\mathrm{N}_{\mathrm{x}}=(a / \mathrm{m} \pi)^{2}\left\{\mathrm{~T}_{33}+\left(2 \mathrm{~T}_{12} \mathrm{~T}_{23} \mathrm{~T}_{13}-\mathrm{T}_{22} \mathrm{~T}_{13}{ }^{2}-\mathrm{T}_{11} \mathrm{~T}_{23}{ }^{2}\right) /\left(\mathrm{T}_{11} \mathrm{~T}_{22}-\mathrm{T}_{12}{ }^{2}\right)\right\}$

with

$\mathrm{T}_{11}=\mathrm{A}_{11}(\mathrm{~m} \pi / a)^{2}+\mathrm{A}_{66}(\mathrm{n} \pi / b)^{2}$

$\mathrm{T}_{12}=\left(\mathrm{A}_{12}+\mathrm{A}_{66}\right)(\mathrm{m} \pi / a)(\mathrm{n} \pi / b)$

$\mathrm{T}_{13}=-\left(3 \mathrm{~B}_{16}(\mathrm{~m} \pi / a)^{2}+\mathrm{B}_{26}(\mathrm{n} \pi / b)^{2}\right)(\mathrm{n} \pi / b)$

$\mathrm{T}_{22}=\mathrm{A}_{22}(\mathrm{n} \pi / b)^{2}+\mathrm{A}_{66}(\mathrm{~m} \pi / a)^{2}$

$\mathrm{T}_{23}=-\left(\mathrm{B}_{16}(\mathrm{~m} \pi / a)^{2}+3 \mathrm{~B}_{26}(\mathrm{n} \pi / b)^{2}\right)(\mathrm{m} \pi / a)$

$\mathrm{T}_{33}=\mathrm{D}_{11}(\mathrm{~m} \pi / a)^{4}+2\left(\mathrm{D}_{12}+2 \mathrm{D}_{66}\right)(\mathrm{m} \pi / a)^{2}(\mathrm{n} \pi / b)^{2}+\mathrm{D}_{22}(\mathrm{n} \pi / b)^{4}$

where, for the infinitely long case, $\mathrm{m}$ is a non-integer value, corresponding to the number of buckling half-waves along the plate length, $a$, or plate width, $b$, when $a=b$ is assumed.

Following minimisation of $\mathrm{N}_{\mathrm{x}}$, with respect to $\mathrm{m}$ and $\mathrm{n}$, the buckling load can be expressed in non-dimensional form: 
$\mathrm{k}_{\mathrm{x}}=\left(\mathrm{N}_{\mathrm{x}} \mathrm{b}^{2}\right) /\left(\pi^{2} \mathrm{D}_{\text {Iso }}\right)$

where $\mathrm{D}_{\text {Iso }}$ is calculated from the laminate invariant, $\mathrm{U}_{1}$, and laminate thickness, $H$ :

$\mathrm{D}_{\text {Iso }}=\mathrm{U}_{1} H^{3} / 12$

This permits like-with-like comparison of laminates with any number of plies, $n$, and is the procedure adopted for generating $\mathrm{k}_{\mathrm{x}}$ in Tables $\mathrm{A} 2$ and $\mathrm{A} 3$, since Eq. (20) degenerates to the closed form solution for orthotropic laminates when $B_{i j}=0$. Note that due to the square symmetric form of the $\mathbf{A}, \mathbf{B}$ and $\mathbf{D}$ matrices in all balanced plain weave laminates, $\mathrm{m}=\mathrm{n}=1$ in Eq. (20), which corresponds to a buckling halfwavelength $\lambda=b$.

Equation (20) is often associated with anti-symmetric angle-ply laminates [26,27], but the non-symmetric stacking sequences presented in Table A3 demonstrate that these conditions are not a requirement. Buckling factors, $\mathrm{k}_{\mathrm{x}}=3.04$ and 3.40, are readily calculated for the comparator laminates with unidirectional and balanced plain weave materials, respectively. A lower $\mathrm{k}_{\mathrm{x}}$ for the unidirectional laminate is expected, since it possesses the highest Extension-Twisting coupling magnitude of the two comparators; Extension-Twisting coupling has been shown [25] to be inversely proportional to the compression buckling strength. Table A3 demonstrates that for laminates with balanced plain weave the maximum coupling magnitude, $\xi_{8}=1$, gives a lower-bound buckling solution, $\mathrm{k}_{\mathrm{x}}=3.40$, for stacking sequences of the form $\left[\alpha_{n / 2} / \beta_{n / 2}\right]_{\mathrm{T}}$. By contrast, the upper-bound buckling solution tends toward $\mathrm{k}_{\mathrm{x}}=4.00$ as lamination parameter, $\xi_{8}$, approaches zero, i.e. the fully isotropic laminate. The stacking sequences in Table A3 possess lamination parameters $\xi_{2}=\xi_{4}=\xi_{10}=\xi_{12}=0$ for all axis rotations, representing extensional and bending isotropy. 


\section{Conclusions}

A definitive list of laminate stacking sequences has been derived for balanced plain weave material with standard ply orientations used in industry.

Seven unique classes of coupled composite laminates have been demonstrated, and for completeness, uncoupled laminates have been included together with an important subgroup possessing fully isotropic properties.

Isotropy in bending and/or extensional stiffness has been found in both coupled as well as uncoupled laminates.

The coupled classes arise from the judicious realignment of the principal material axis of a so-called parent laminate class, which possesses Extension-Bending and ShearingTwisting: off-axis alignment, with respect to the structural or system axis, gives rise to other distinct forms of coupling interaction.

All seven classes of coupled balanced plain weave laminate have immunity to thermal warping distortions, which generally arise as a result of the high temperature curing process. Such laminates therefore provide a robust manufacturing solution for integrating complex mechanical coupling response, as an enabling technology, in future smart materials and structures. 


\section{References}

[1] Nixon, M.W., 1987. Extension-twist coupling of composite circular tubes with application to tilt rotor blade design, 28th AIAA/ASME/ASCE/AHS/ASC Structures, Structural Dynamics, and Materials, Monterey, United states, Paper No. AIAA-870772 .

[2] Winckler, S.J., 1985. Hygrothermally Curvature Stable Laminates with TensionTorsion Coupling. Journal of the American Helicopter Society, 30, 56-58.

[3] York, C.B., 2010. Unified approach to the characterization of coupled composite laminates: Benchmark configurations and special cases. Journal of Aerospace Engineering, 23, 219-242.

[4] Tsai, S.W., Hahn, H.T., 1980. Introduction To Composite Materials. Technomic Publishing Co. Inc., Lancaster.

[5] Chen, H.P., 2003. Study of hygrothermal isotropic layup and hygrothermal curvature-stable coupling composite laminates, 44th AIAA/ASME/ASCE/AHS/ASC Structures, Structural Dynamics, and Materials Conference. American Inst. Aeronautics and Astronautics Inc., Norfolk, VA, United States, 958-967.

[6] Cross, R.J., Haynes, R.A., Armanios, E.A., 2008. Families of Hygrothermally Stable Asymmetric Laminated Composites. Journal of Composite Materials, 42, 697-716.

[7] Diaconu, C.G., Sekine, H., 2003. Flexural Characteristics and Layup Optimization of Laminated Composite Plates Under Hygrothermal Conditions using Lamination Parameters, Journal of Thermal Stresses, 26, 905-922. 
[8] Diaconu, C.G., Sekine, H., 2004. Erratum on Flexural Characteristics and Layup Optimization of Laminated Composite Plates Under Hygrothermal Conditions using Lamination Parameters, Journal of Thermal Stresses, 27, 1213-1216.

[9] Weaver, P.M., 2005. Anisotropic laminates that resist warping during manufacture, $15^{\text {th }}$ International Conference on Composite Materials, Durban, South Africa.

[10] York, C.B., 2011. Unified approach to the characterization of coupled composite laminates Hygro-thermally curvature-stable configurations. International Journal of Structural Integrity, 2, 406-436.

[11] Verchery, G., 2011. Design Rules for the Laminate Stiffness. Mechanics of Composite Materials, 47, 47-58.

[12] Shamsudin, M.H., Rousseau, J., York, C.B., 2013. Warping Curvature Predictions for Non-Symmetric Woven Cloth Laminates. Proc. 12th Deformation and Fracture of Composites and 6th Structural Integrity and Multi-scale Modelling Conf., Cambridge, England.

[13] Ishikawa, T., Chou, T.W., 1982. Stiffness and strength behaviour of woven fabric composites. Journal of Materials Science, 17, 3211-3220.

[14] Naik, N.K., Shembekar, P.S., 1992. Elastic Behavior of Woven Fabric Composites: I - Lamina Analysis. Journal of Composite Materials, 26, 2196-2225.

[15] Raju, I.S., Wang, J.T., 1994. Classical laminate theory models for woven fabric composites. Journal of Composites Technology and Research, 16, 289-303.

[16] Naik, N.K., Shembekar, P.S., 1992. Elastic Behavior of Woven Fabric Composites: III - Laminate Design. Journal of Composite Materials, 26, 2522-2541. 
[17] Ishikawa, T., Matsushima, M., Hayashi, Y., Chou, T.W., 1985. Experimental Confirmation of the Theory of Elastic Moduli of Fabric Composites. Journal of Composite Materials, 19, 443-458.

[18] Jekabsons, N., Byström, J., 2002. On the effect of stacked fabric layers on the stiffness of a woven composite. Composites Part B: Engineering, 33, 619-629.

[19] ESDU, 1994. Stiffnesses of laminated flat plates Engineering Science Data Unit Item No. 94003, 1-28.

[20] Shamsudin, M.H., Roussea, J., Verchery, G., York, C.B., 2011. Experimental Validation of the Mechanical Coupling Response for Hygro-Thermally CurvatureStable Laminated Composite Materials, 6th International Conference on Supply on the Wings, Frankfurt, Germany.

[21] Vincenti, A., Verchery, G., Vannucci, P., 2001. Anisotropy and symmetry for elastic properties of laminates reinforced by balanced fabrics. Composites Part A: Applied Science and Manufacturing, 32, 1525-1532.

[22] Verchery, G., 1979. Les invariants d'ordre 4 du type de l'elasticité. Euromech Colloquium 115, Villard-de-Lans, France, 93-104.

[23] Grediac, M., 2001. On the stiffness design of thin woven composites. Composite Structures, 51, 245-255.

[24] York, C.B., 2013. Tapered hygo-thermally curvature-stable laminates with nonstandard ply orientations. Composites Part A: Applied Science and Manufacturing, 44, 140-148 
[25] Shamsudin, M.H., Chen, J., York, C.B., 2013. Bounds on the Compression Buckling Strength of Hygro-Thermally Curvature-Stable Laminate with ExtensionTwisting Coupling. International Journal of Structural Integrity. In Press.

[26] Whitney, J.M., Leissa, A.W., 1969. Analysis of Heterogenous Anisotropic Plates. Journal of Applied Mechanics, 36, 261-266.

[27] Jones, R.M., 1999. Mechanics of Composite Materials, 2nd Edition ed. Blacksburg. Taylor \& Francis, Inc., Virginia. 
1

2

3

4

5

6

7

8

10

11

12

13

14

15

16

17

18

19

20

21

22

23

24

25

26

27

28

29

30

31

32

33

34

35

36

37

38

39

40

41

42

43

44

45

46

47

48

49

50

51

52

53

54

55

56

57

58

59

60

61

62

63

64

65

\section{Figures}
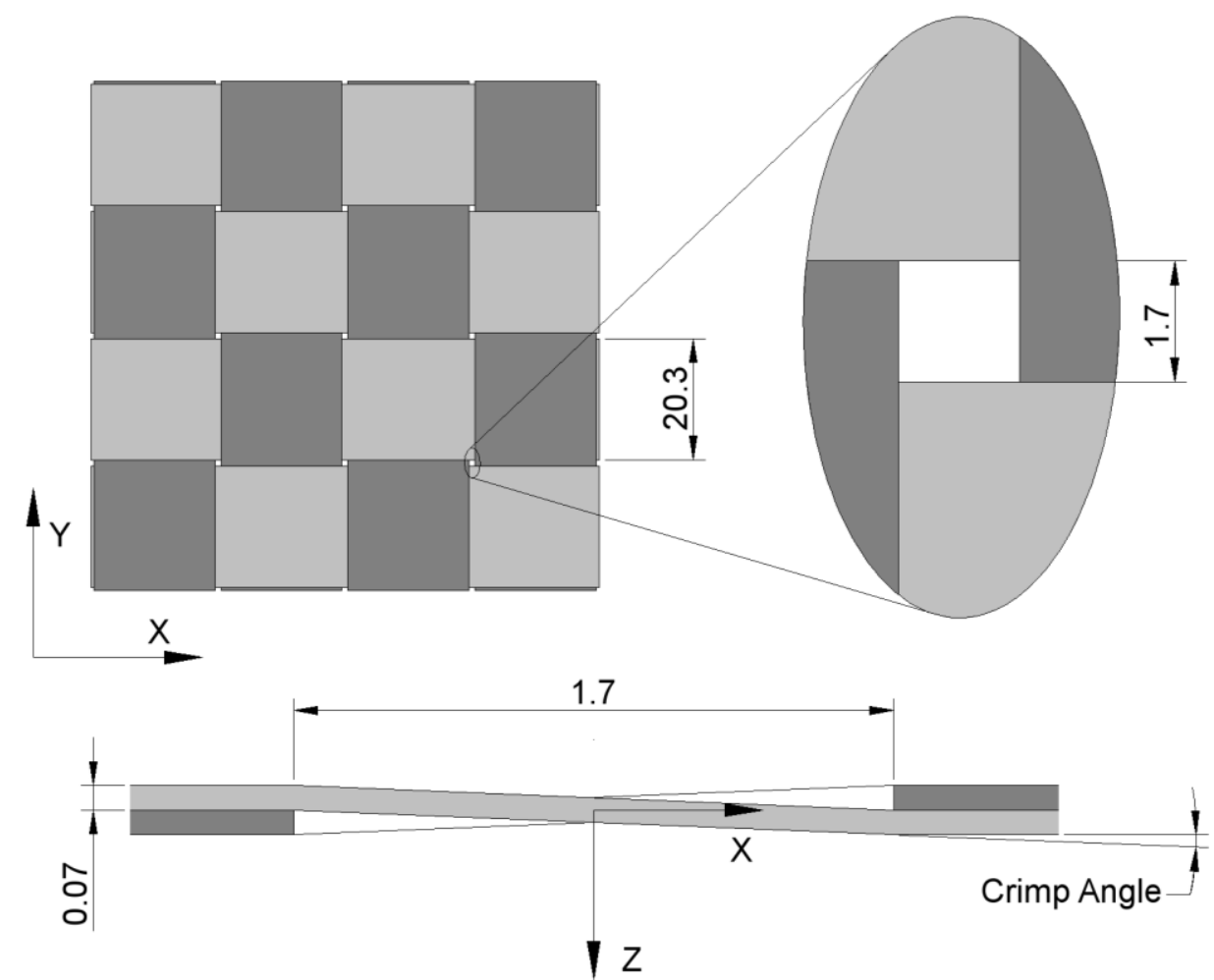

Figure 1 


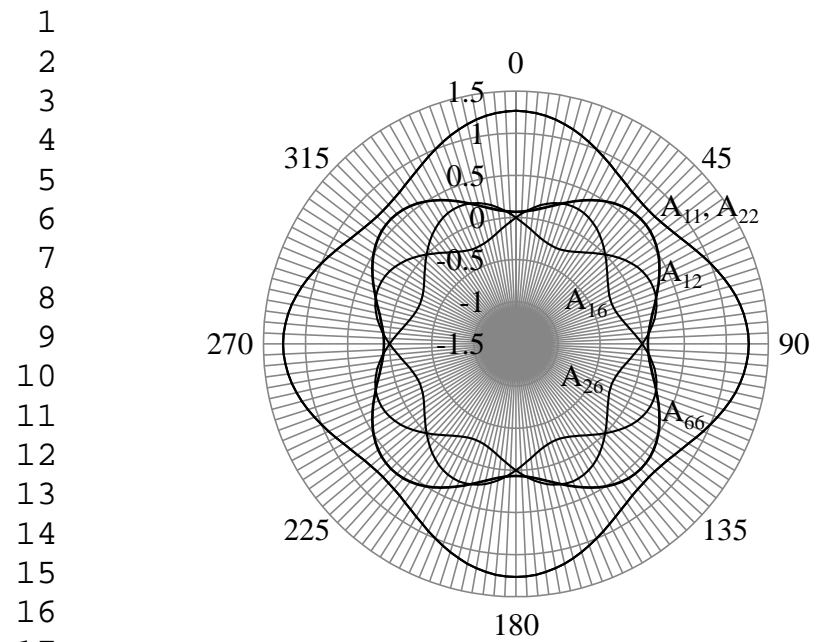

(a)

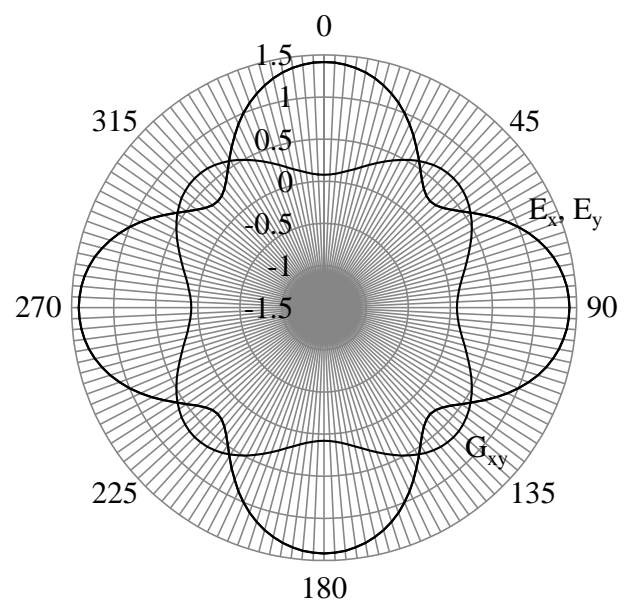

(c)

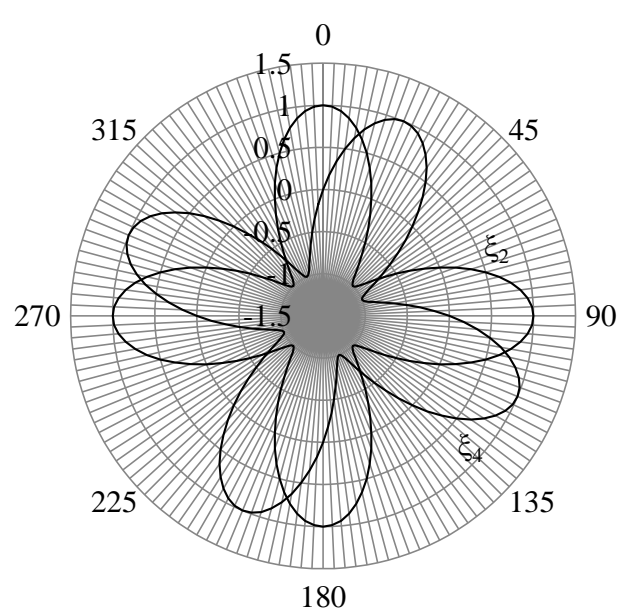

(b)

Figure 2 


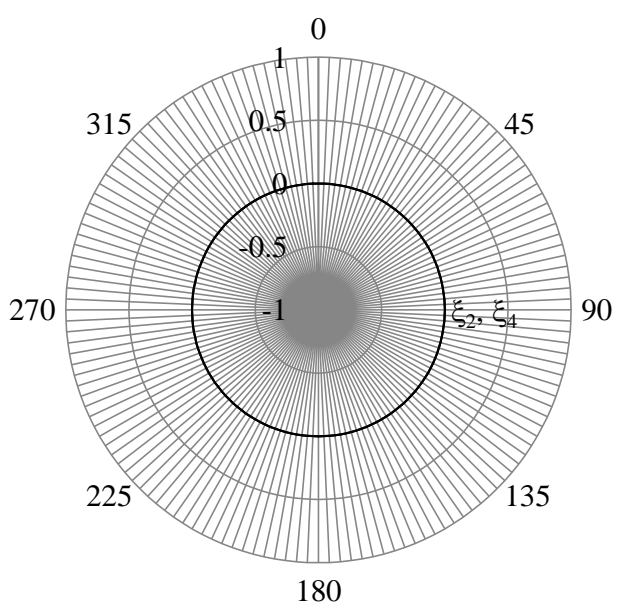

(a)

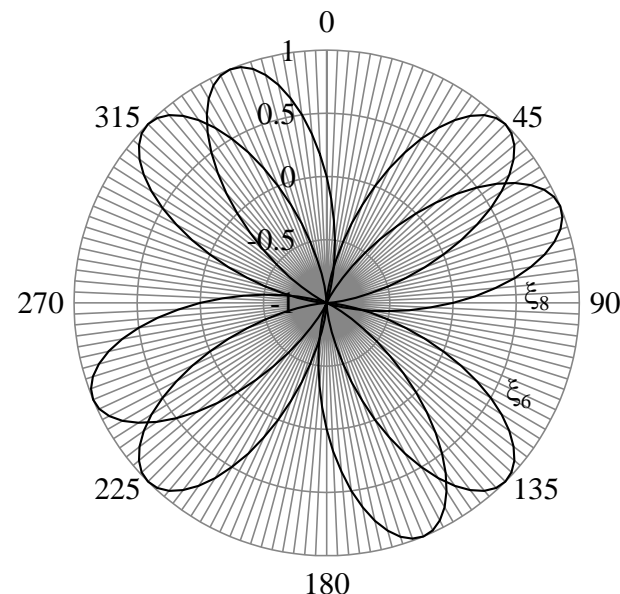

(b)

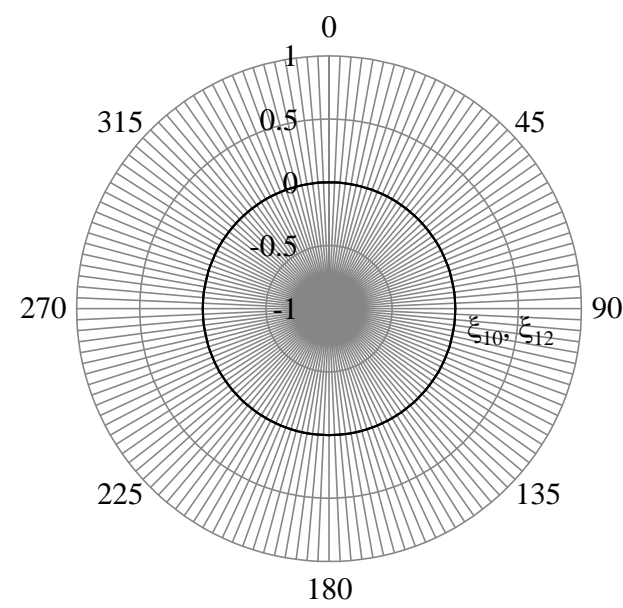

(c)

Figure 3 


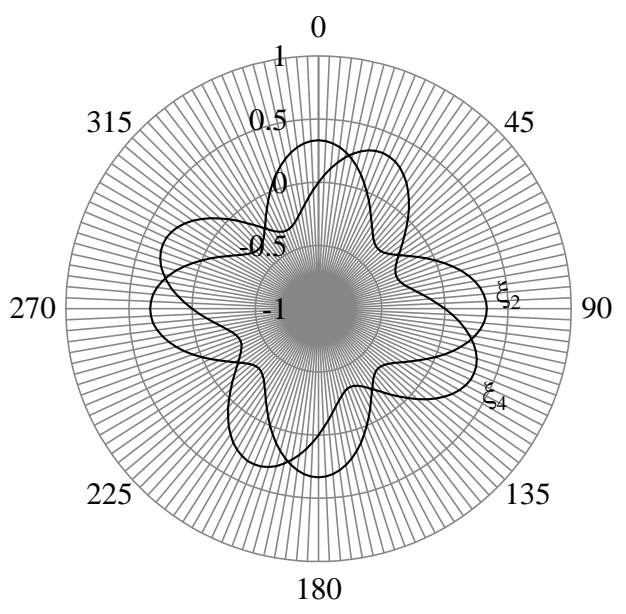

(a)

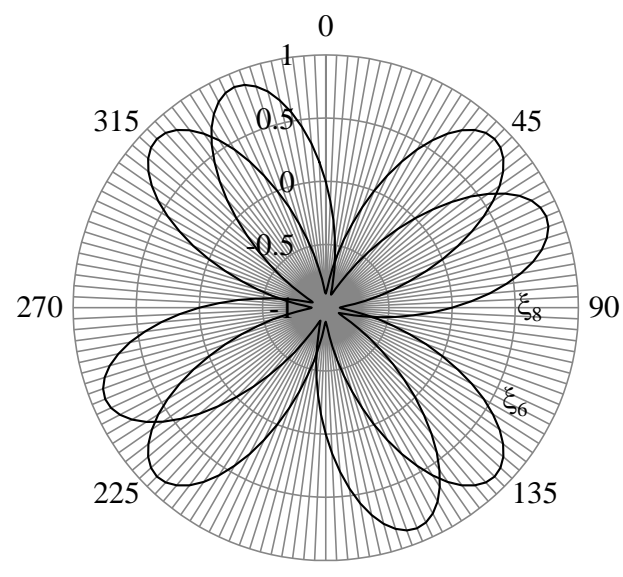

180

(b)

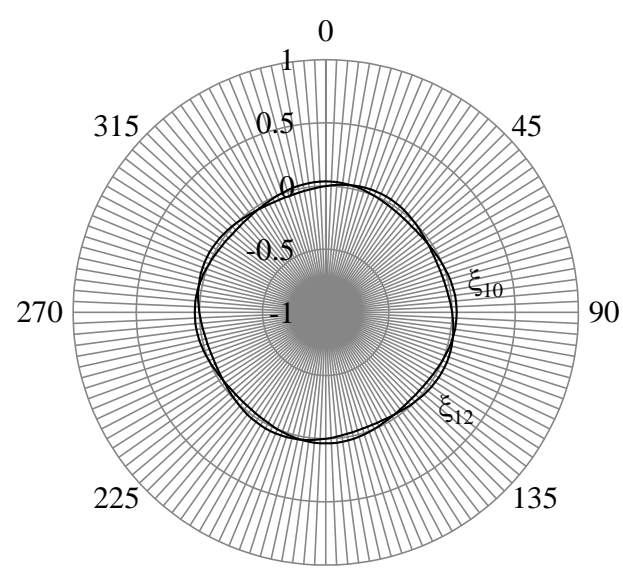

180

(c)

Figure 4 


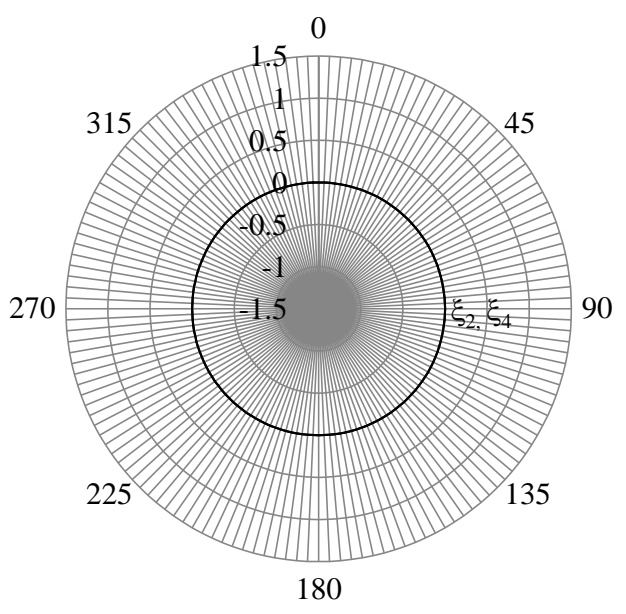

(a)

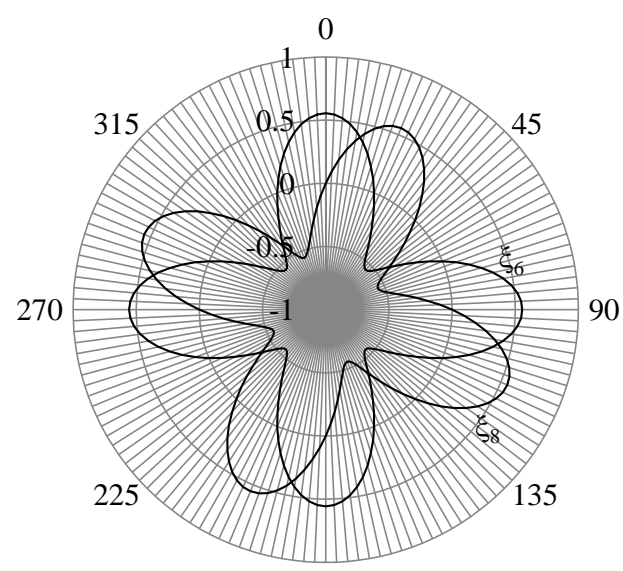

180

(b)

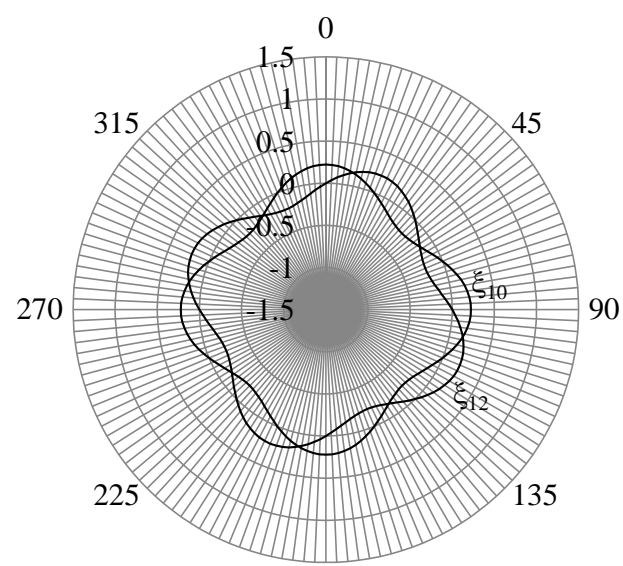

180

(c)

Figure 5 
1

2

3

4

5

6

7

8

10

11

12

13

14

15

16

17

18

19

20

21

22

23

24

25

26

27

28

29

30

31

32

33

34

35

36

37

38

39

40

41

42

43

44

45

46

47

48

49

50

51

52

53

54

55

56

57

58

59

60

61

62

63

64

65

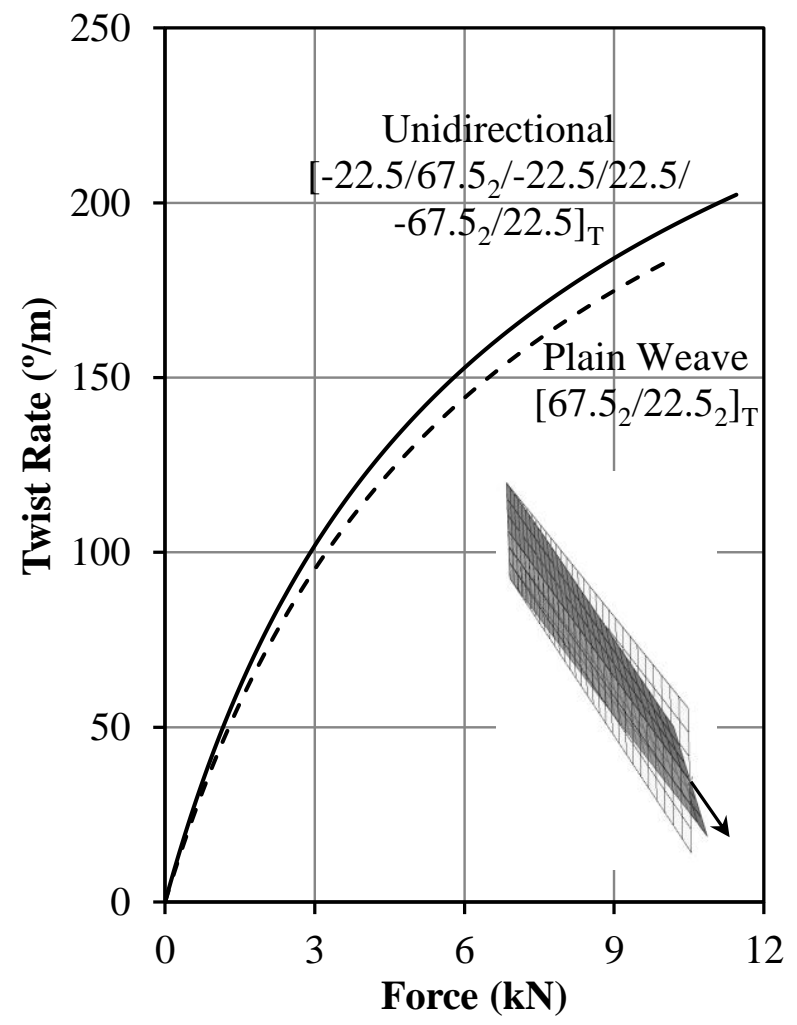

Figure 6. 


\section{Figure Captions}

Figure 1 - Balanced plain weave architecture, illustrating a plan view of a representative volume element with exploded details. Dimensions provided are representative of $\left(\mathrm{TeXtreme}^{\circledR}\right)$ spread tow fabric with $70 \mu \mathrm{m}$ tape thickness and $2.5^{\circ}$ crimp angle.

Figure 2 - Polar plots for off-axis material alignment, $0^{\circ} \leq \beta \leq 360^{\circ}$, of: (a) extensional stiffness, $\mathrm{A}_{\mathrm{ij}}$; lamination parameters, $\xi_{2}, \xi_{4}$ and; effective moduli for a single layer of balanced plain weave, $\mathrm{E}_{\mathrm{x}}=\mathrm{E}_{\mathrm{y}}=\left(\mathrm{A}_{11} \mathrm{~A}_{22}-\mathrm{A}_{12}{ }^{2}\right) / \mathrm{A}_{22} t$ and $\mathrm{G}_{\mathrm{xy}}=\mathrm{A}_{66} / t$.

Figure 3 - Polar plots of the lamination parameters corresponding to: (a) A (b) B and (c) D stiffness properties with off-axis material alignment, $0^{\circ} \leq \beta \leq 360^{\circ}$, for 2-ply $\mathbf{A}_{\mathrm{I}} \mathbf{B}_{\mathrm{S}} \mathbf{D}_{\mathrm{I}}$ balanced plain weave laminate stacking sequence $[\alpha / \beta]_{\mathrm{T}}$, where $\alpha=\beta+\pi / 4$.

Figure 4 - Polar plots of the lamination parameters for: (a) A (b) $\mathbf{B}$ and (c) D matrices corresponding to off-axis material alignment, $0^{\circ} \leq \beta \leq 360^{\circ}$, for 3-ply $\mathbf{A}_{\mathrm{S}} \mathbf{B}_{\mathrm{S}} \mathbf{D}_{\mathrm{S}}$ laminate stacking sequence $\left[\alpha / \beta_{2}\right]_{\mathrm{T}}$, where $\alpha=\beta+\pi / 4$.

Figure 5 - Polar plots of the lamination parameters for: (a) A (b) B and (c) D matrix corresponding to off-axis material alignment, $0^{\circ} \leq \beta \leq 360^{\circ}$, for 6-ply $\mathbf{A}_{\mathrm{I}} \mathbf{B}_{\mathrm{S}} \mathbf{D}_{\mathrm{S}}$ laminate stacking sequence $\left[\alpha / \beta / \alpha_{2} / \beta_{2}\right]_{\mathrm{T}}$, where $\alpha=\beta+\pi / 4$. 
Figure 6 - Twist Rate vs Axial Force for the unidirectional and balanced plain weave laminate comparators with equal thickness. 
Tables

Table 1 - Property comparisons for unidirectional and balanced plain weave $\left(\right.$ Hexcel $^{\mathrm{TM}}$ ) intermediate (60\% fibre volume) modulus carbon/epoxy materials. Values in parentheses indicate compressive moduli.

\begin{tabular}{ccc}
\hline Properties & Unidirectional & Plain Weave \\
\hline \hline $\mathrm{E}_{1}$ & $170(150) \mathrm{GPa}$ & $90(80) \mathrm{GPa}$ \\
$\mathrm{E}_{2}$ & $9(11) \mathrm{GPa}$ & $90(80 *) \mathrm{GPa}$ \\
$\mathrm{G}_{12}$ & $4.4 \mathrm{GPa}$ & $5 \mathrm{GPa}$ \\
$v_{12}$ & 0.27 & 0.05 \\
$t$ & $0.183 \mathrm{~mm}$ & $0.366 \mathrm{~mm}$ \\
$\sigma_{1}{ }^{\mathrm{T}}$ & $2,400 \mathrm{MPa}$ & $900 \mathrm{MPa}$ \\
$\sigma_{1}{ }^{\mathrm{C}}$ & $-1,600 \mathrm{MPa}$ & $-800 \mathrm{MPa}$ \\
$\sigma_{2}{ }^{\mathrm{T}}$ & $80 \mathrm{MPa}$ & $850 \mathrm{MPa}$ \\
$\sigma_{2}{ }^{\mathrm{C}}$ & $-250 \mathrm{MPa}$ & $-750 \mathrm{MPa}$ \\
$\tau_{12}{ }^{\mathrm{F}}$ & $95 \mathrm{MPa}$ & $80 \mathrm{MPa}$ \\
\hline $\mathrm{E}_{2}=\mathrm{E}_{1}$ assumed instead of published value, $\mathrm{E}_{2}=75 \mathrm{GPa}$.
\end{tabular}


Table 2 - Square symmetric forms of the Extensional $[\mathbf{A}]$ and Bending [D] stiffness matrices for uncoupled (Simple) with $\beta=m \pi / 4$ and coupled behaviour with $\beta \neq m \pi / 4$.

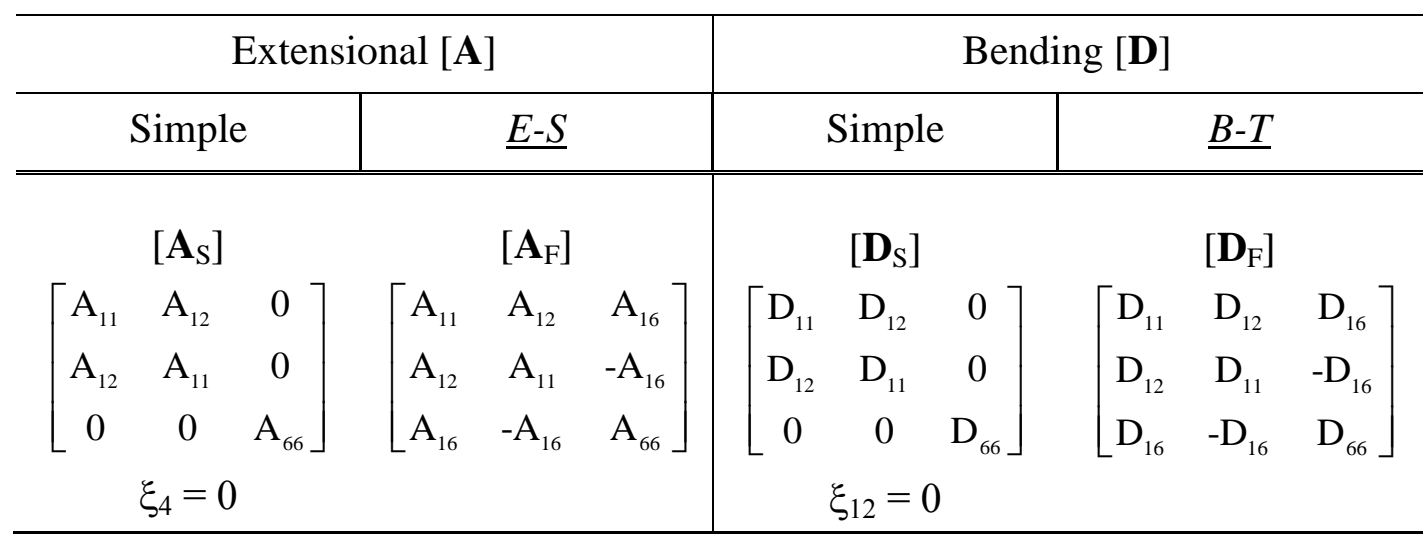


Table 3 - Coupling [B] stiffness matrices with square symmetry, and associated causeeffect relationship, subscript notation and lamination parameter constraints, for coupled behaviour with respect to material axis alignment, $\beta$.

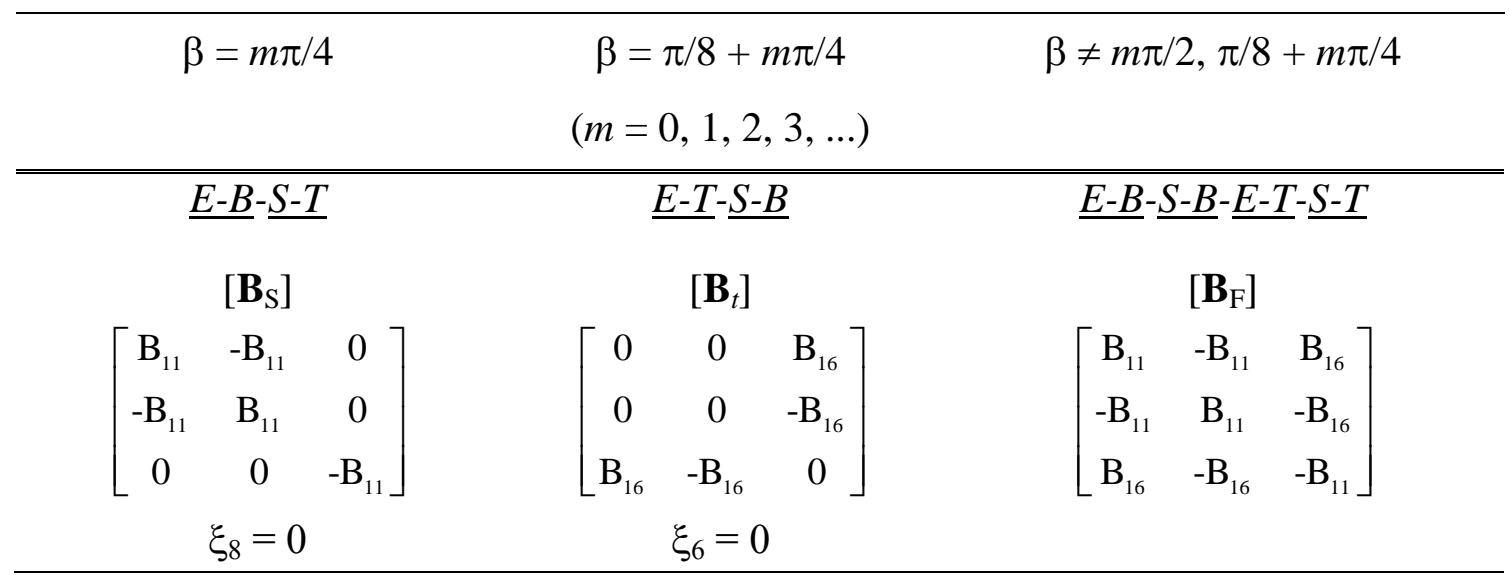


Table 4 - Comparisons of stiffness and compliance matrices for different cause-effect relationships. Note that $\alpha=\beta+\pi / 4$ in stacking sequence definition.

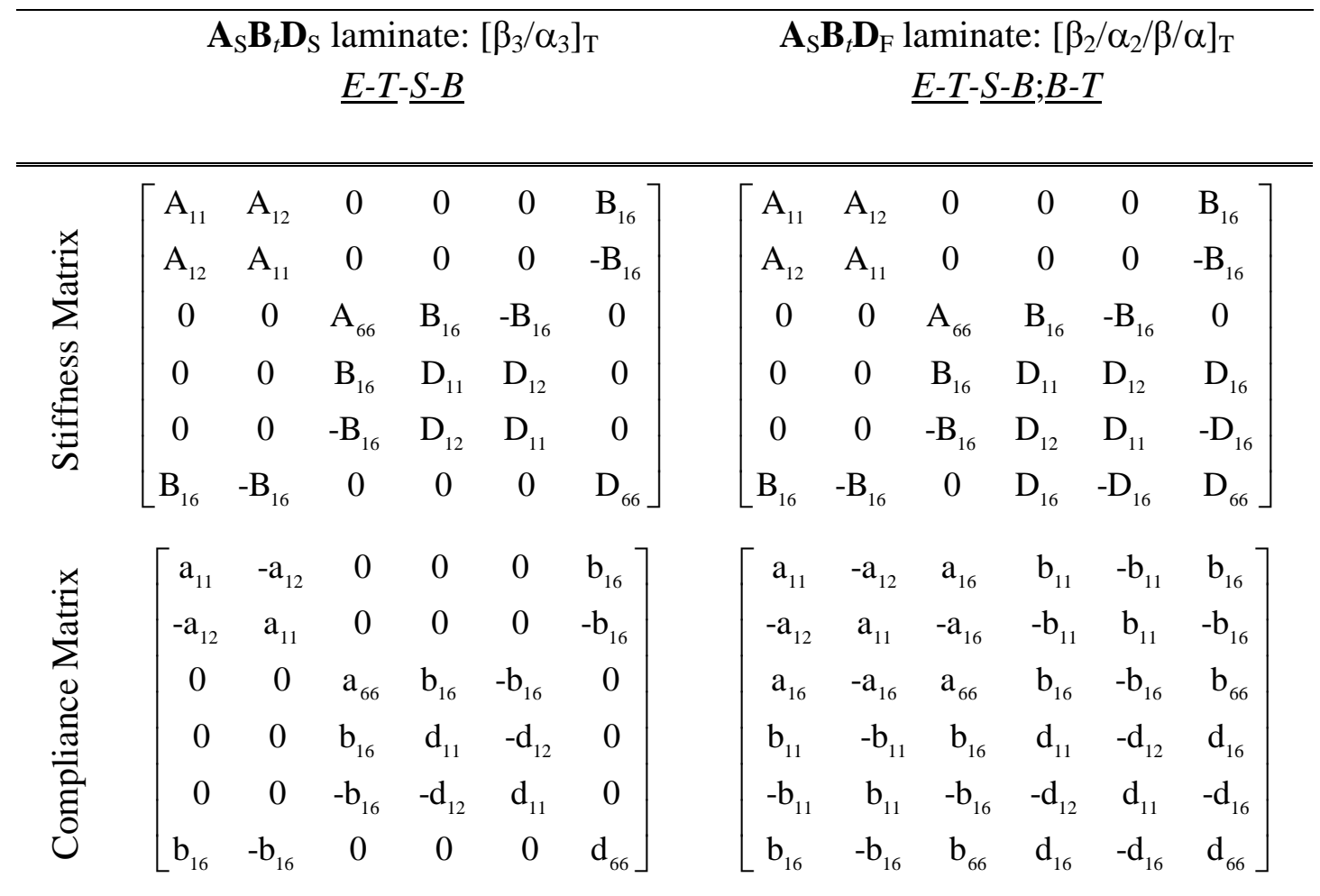


Table 5 - Summary on the number of Simple, uncoupled $\left(\mathbf{A}_{S} \mathbf{B}_{0} \mathbf{D}_{S}\right)$ laminates for each ply number grouping, $n$, and the number that possess quasi-homogeneous $\left(\mathbf{A}_{S} \mathbf{B}_{0} \mathbf{D}_{S}\right)$, fully isotropic $\left(\mathbf{A}_{\mathrm{I}} \mathbf{B}_{0} \mathbf{D}_{\mathrm{I}}\right)$ or extensionally isotropic $\left(\mathbf{A}_{\mathrm{I}} \mathbf{B}_{0} \mathbf{D}_{\mathrm{S}}\right)$ properties.

\begin{tabular}{ccccc}
\hline$n$ & $\begin{array}{c}\text { Simple } \\
\mathbf{A}_{\mathrm{S}} \mathbf{B}_{0} \mathbf{D}_{\mathrm{S}}\end{array}$ & $\begin{array}{c}\text { Quasi-homogeneous } \\
\mathbf{A}_{\mathrm{S}} \mathbf{B}_{0} \mathbf{D}_{\mathrm{S}}\end{array}$ & $\begin{array}{c}\text { Fully Isotropic } \\
\mathbf{A}_{\mathrm{I}} \mathbf{B}_{0} \mathbf{D}_{\mathrm{I}}\end{array}$ & $\begin{array}{c}\text { Extensionally Isotropic } \\
\mathbf{A}_{\mathrm{I}} \mathbf{B}_{0} \mathbf{D}_{\mathrm{S}}\end{array}$ \\
\hline \hline 2 & 1 & 1 & & \\
3 & 2 & 1 & & \\
4 & 2 & 1 & & \\
5 & 4 & 1 & & \\
6 & 4 & 1 & & \\
7 & 10 & 2 & & \\
8 & 9 & 1 & & \\
9 & 26 & 1 & & \\
10 & 24 & 1 & & \\
11 & 76 & 5 & & \\
12 & 69 & 1 & & \\
13 & 236 & 12 & & \\
14 & 214 & 7 & & \\
15 & 760 & 12 & & \\
16 & 696 & 7 & & \\
17 & 2522 & 53 & & \\
18 & 2326 & 22 & & \\
19 & 8556 & 122 & & \\
20 & 7942 & 67 & & \\
21 & 29504 & 99 & & \\
\hline
\end{tabular}


Table 6 - Fully isotropic $\left(\mathbf{A}_{I} \mathbf{B}_{0} \mathbf{D}_{\mathrm{I}}\right)$ laminates for each ply number groupings, $n$, with $\alpha=$ $\beta+\pi / 4$

\begin{tabular}{|c|c|}
\hline$n$ & Stacking sequence \\
\hline 8 & {$\left[\alpha / \beta_{2} / \alpha / \beta / \alpha_{2} / \beta\right]_{\mathrm{T}}$} \\
\hline \multirow[t]{2}{*}{12} & {$\left[\alpha / \beta / \alpha / \beta_{3} / \alpha_{3} / \beta / \alpha / \beta\right]_{\mathrm{T}}$} \\
\hline & $\begin{array}{l}{\left[\alpha / \beta_{3} / \alpha_{4} / \beta_{2} / \alpha / \beta_{2} / \alpha / \beta / \alpha\right]_{\mathrm{T}}} \\
{\left[\alpha / \beta_{2} / \alpha / \beta / \alpha_{2} / \beta_{2} / \alpha_{2} / \beta / \alpha / \beta_{2} / \alpha\right]_{\mathrm{T}}} \\
{\left[\alpha / \beta_{2} / \alpha / \beta / \alpha_{2} / \beta / \alpha / \beta_{2} / \alpha / \beta / \alpha_{2} / \beta\right]_{\mathrm{T}}}\end{array}$ \\
\hline \multirow[t]{2}{*}{16} & $\begin{array}{l}{\left[\alpha / \beta_{2} / \alpha_{2} / \beta_{2} / \alpha / \beta / \alpha_{2} / \beta_{2} / \alpha_{2} / \beta\right]_{\mathrm{T}}} \\
{\left[\alpha / \beta / \alpha / \beta_{2} / \alpha / \beta_{2} / \alpha_{4} / \beta_{3} / \alpha\right]_{\mathrm{T}}} \\
{\left[\alpha / \beta / \alpha / \beta_{2} / \alpha / \beta / \alpha / \beta / \alpha / \beta / \alpha_{2} / \beta / \alpha / \beta\right]_{\mathrm{T}}} \\
{\left[\alpha_{2} / \beta_{4} / \alpha_{2} / \beta_{2} / \alpha_{4} / \beta_{2}\right]_{\mathrm{T}}}\end{array}$ \\
\hline & $\begin{array}{l}{\left[\alpha_{2} / \beta / \alpha / \beta_{5} / \alpha / \beta / \alpha_{5} / \beta / \alpha / \beta_{2}\right]_{\mathrm{T}}} \\
{\left[\alpha_{2} / \beta_{2} / \alpha / \beta_{3} / \alpha / \beta / \alpha / \beta / \alpha_{3} / \beta / \alpha_{2} / \beta_{2}\right]_{\mathrm{T}}} \\
{\left[\alpha_{2} / \beta_{3} / \alpha / \beta / \alpha / \beta_{2} / \alpha_{2} / \beta / \alpha / \beta / \alpha_{3} / \beta_{2}\right]_{\mathrm{T}}} \\
{\left[\alpha / \beta_{2} / \alpha_{2} / \beta / \alpha / \beta / \alpha / \beta_{3} / \alpha / \beta / \alpha_{4} / \beta_{2}\right]_{\mathrm{T}}} \\
{\left[\alpha / \beta / \alpha_{2} / \beta_{4} / \alpha / \beta / \alpha / \beta / \alpha_{4} / \beta_{2} / \alpha / \beta\right]_{\mathrm{T}}} \\
{\left[\alpha / \beta / \alpha / \beta / \alpha / \beta / \alpha / \beta_{4} / \alpha_{5} / \beta_{2} / \alpha / \beta\right]_{\mathrm{T}}} \\
{\left[\alpha / \beta / \alpha_{2} / \beta_{5} / \alpha_{4} / \beta / \alpha / \beta / \alpha / \beta / \alpha / \beta\right]_{\mathrm{T}}} \\
{\left[\alpha / \beta / \alpha / \beta / \alpha / \beta_{2} / \alpha / \beta_{2} / \alpha_{2} / \beta / \alpha_{2} / \beta / \alpha / \beta / \alpha / \beta\right]_{\mathrm{T}}} \\
{\left[\alpha / \beta / \alpha / \beta_{2} / \alpha_{2} / \beta_{2} / \alpha / \beta_{2} / \alpha_{3} / \beta / \alpha / \beta / \alpha / \beta\right]_{\mathrm{T}}} \\
{\left[\alpha / \beta / \alpha / \beta / \alpha / \beta_{3} / \alpha_{2} / \beta / \alpha_{2} / \beta_{2} / \alpha_{2} / \beta / \alpha / \beta\right]_{\mathrm{T}}} \\
{\left[\alpha / \beta / \alpha / \beta_{2} / \alpha_{2} / \beta_{3} / \alpha_{3} / \beta_{2} / \alpha_{2} / \beta / \alpha / \beta\right]_{\mathrm{T}}}\end{array}$ \\
\hline \multirow[t]{12}{*}{20} & {$\left[\alpha / \beta / \alpha / \beta_{3} / \alpha_{4} / \beta_{4} / \alpha_{3} / \beta / \alpha / \beta\right]_{\mathrm{T}}$} \\
\hline & {$\left[\alpha_{2} / \beta_{4} / \alpha / \beta / \alpha_{3} / \beta / \alpha / \beta / \alpha / \beta_{2} / \alpha_{2} / \beta\right]_{\mathrm{T}}$} \\
\hline & {$\left[\alpha / \beta_{2} / \alpha_{2} / \beta / \alpha / \beta_{3} / \alpha_{3} / \beta / \alpha / \beta_{2} / \alpha_{2} / \beta\right]_{\mathrm{T}}$} \\
\hline & {$\left[\alpha / \beta / \alpha / \beta_{3} / \alpha_{3} / \beta / \alpha / \beta / \alpha / \beta_{2} / \alpha / \beta / \alpha_{2} / \beta\right]_{\mathrm{T}}$} \\
\hline & {$\left[\alpha / \beta_{2} / \alpha / \beta / \alpha / \beta / \alpha_{3} / \beta_{3} / \alpha / \beta / \alpha / \beta / \alpha_{2} / \beta\right]_{\mathrm{T}}$} \\
\hline & {$\left[\alpha / \beta_{3} / \alpha_{3} / \beta / \alpha_{2} / \beta_{2} / \alpha / \beta_{3} / \alpha_{3} / \beta\right]_{\mathrm{T}}$} \\
\hline & {$\left[\alpha / \beta / \alpha / \beta / \alpha / \beta_{3} / \alpha / \beta / \alpha_{4} / \beta_{2} / \alpha / \beta_{2} / \alpha\right]_{\mathrm{T}}$} \\
\hline & {$\left[\alpha / \beta / \alpha / \beta_{3} / \alpha_{3} / \beta / \alpha / \beta_{2} / \alpha_{2} / \beta / \alpha / \beta_{2} / \alpha\right]_{\mathrm{T}}$} \\
\hline & {$\left[\alpha_{2} / \beta_{5} / \alpha_{5} / \beta / \alpha / \beta_{3} / \alpha / \beta / \alpha\right]_{\mathrm{T}}$} \\
\hline & {$\left[\alpha / \beta_{2} / \alpha / \beta / \alpha_{2} / \beta_{2} / \alpha / \beta / \alpha_{3} / \beta_{3} / \alpha / \beta / \alpha\right]_{\mathrm{T}}$} \\
\hline & {$\left[\alpha / \beta_{2} / \alpha / \beta_{2} / \alpha_{4} / \beta / \alpha / \beta_{3} / \alpha / \beta / \alpha / \beta / \alpha\right]_{\mathrm{T}}$} \\
\hline & {$\left[\alpha / \beta / \alpha / \beta_{3} / \alpha / \beta / \alpha_{5} / \beta_{5} / \alpha_{2}\right]_{\mathrm{T}}$} \\
\hline
\end{tabular}


Table 7 - Classification of coupled laminates with balance plain weave, derived from the $\mathbf{A}_{S} \mathbf{B}_{S} \mathbf{D}_{\mathrm{S}}$ parent laminate with Bending-Extension and Twisting-Shearing $(\underline{B-E-\underline{T-S}})$ coupling, following off-axis material alignment, $\beta$. Illustrations highlight the coupling responses due to free thermal contraction in unbalanced plain weave. For stacking sequence definition, $\alpha=\beta+\pi / 4$.

\begin{tabular}{|c|c|c|c|}
\hline \multicolumn{2}{|c|}{ Uncoupled in Extension $\left[\mathbf{A}_{S}\right]$} & Extension-Shearing & \\
\hline $\begin{array}{c}\text { Uncoupled in Bending } \\
{\left[\mathbf{D}_{\mathrm{S}}\right]}\end{array}$ & Bending-Twisting $\left[\mathrm{D}_{\mathrm{F}}\right]$ & $\begin{array}{c}\text { Bending-Twisting } \\
{\left[\mathrm{D}_{\mathrm{F}}\right]}\end{array}$ & \\
\hline $\begin{array}{c}\mathbf{A}_{\mathrm{S}} \mathbf{B}_{t} \mathbf{D}_{\mathrm{S}} \\
{[\alpha / \beta]_{\mathrm{T}}}\end{array}$ & $\begin{array}{c}\mathbf{A}_{\mathrm{S}} \mathbf{B}_{t} \mathbf{D}_{\mathrm{F}} \\
{\left[\alpha / \beta / \alpha_{2} / \beta_{2}\right]_{\mathrm{T}}}\end{array}$ & $\underline{E-S} ; \underline{B-S}-\underline{T-E} ; \underline{B-T}$ & 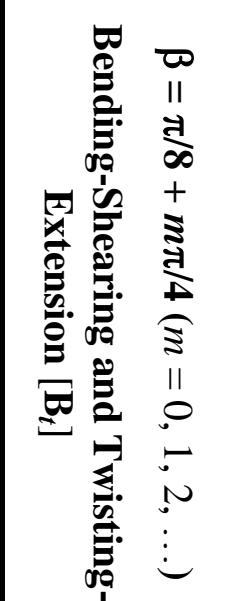 \\
\hline 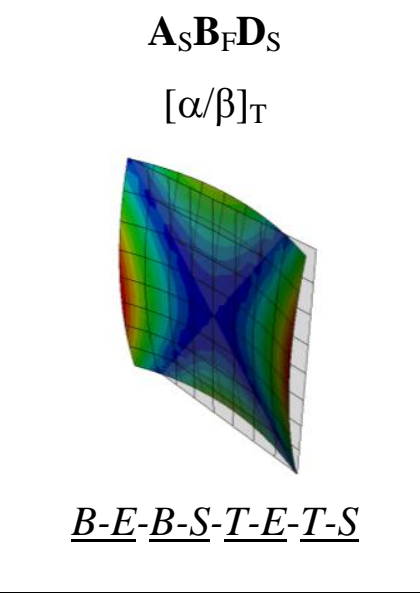 & $\begin{array}{c}\mathbf{A}_{\mathrm{S}} \mathbf{B}_{\mathrm{F}} \mathbf{D}_{\mathrm{F}} \\
{\left[\alpha / \beta / \alpha_{2} / \beta_{2}\right]_{\mathrm{T}}} \\
\end{array}$ & $\underline{E-S} ; \frac{B-E-B-S}{\underline{S}} ; \underline{B-T} \underline{\underline{B-E}}-\underline{T-}$ & 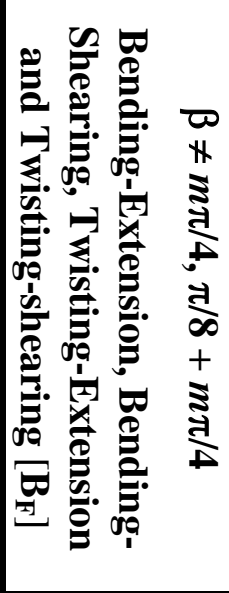 \\
\hline
\end{tabular}


Table 8 - Number of solutions for the $\underline{E-B}-\underline{S-T}$ or $\underline{B-E-T-S}$ coupled parent $\left(\mathrm{A}_{S} \mathrm{~B}_{\mathrm{S}} \mathrm{D}_{\mathrm{S}}\right)$ laminate class for each ply number grouping, $n$, and number of solutions in each of the six other coupled laminate derivatives of Table 7, following off-axis alignment, $\beta$.

\begin{tabular}{|c|c|c|c|c|c|c|c|}
\hline \multirow[b]{3}{*}{$n$} & \multicolumn{7}{|c|}{ Number of solutions } \\
\hline & $\mathbf{A}_{\mathrm{S}} \mathbf{B}_{\mathrm{S}} \mathbf{D}_{\mathrm{S}}$ & $\mathbf{A}_{\mathrm{S}} \mathbf{B}_{t} \mathbf{D}_{\mathrm{S}}$ & $\mathbf{A}_{\mathrm{S}} \mathbf{B}_{t} \mathbf{D}_{\mathrm{F}}$ & $\mathbf{A}_{\mathrm{F}} \mathbf{B}_{t} \mathbf{D}_{\mathrm{F}}$ & $\mathbf{A}_{\mathrm{S}} \mathbf{B}_{\mathrm{F}} \mathbf{D}_{\mathrm{S}}$ & $\mathbf{A}_{\mathrm{S}} \mathbf{B}_{\mathrm{F}} \mathbf{D}_{\mathrm{F}}$ & $\mathbf{A}_{\mathrm{F}} \mathbf{B}_{\mathrm{F}} \mathbf{D}_{\mathrm{F}}$ \\
\hline & $\beta=0$ & \multicolumn{3}{|c|}{$\begin{array}{c}\beta=\pi / 8+m \pi / 4 \\
(m=0,1,2,3, \ldots)\end{array}$} & \multicolumn{3}{|c|}{$\begin{array}{c}\beta \neq m \pi / 4, \pi / 8+m \pi / 2 \\
(m=0,1,2,3, \ldots)\end{array}$} \\
\hline 2 & 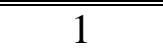 & 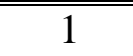 & & & 1 & & \\
\hline 3 & 2 & & & 2 & & & 2 \\
\hline 4 & 6 & 2 & & 4 & 2 & & 4 \\
\hline 5 & 12 & & & 12 & & & 12 \\
\hline 6 & 28 & 4 & 6 & 18 & 4 & 6 & 18 \\
\hline 7 & 54 & & & 54 & & & 54 \\
\hline 8 & 119 & 7 & 24 & 88 & 7 & 24 & 88 \\
\hline 9 & 230 & & & 230 & & & 230 \\
\hline 10 & 488 & 16 & 110 & 362 & 16 & 110 & 362 \\
\hline 11 & 948 & & & 948 & & & 948 \\
\hline 12 & 1979 & 35 & 398 & 1546 & 35 & 398 & 1546 \\
\hline 13 & 3860 & & & 3860 & & & 3860 \\
\hline 14 & 7978 & 84 & 1632 & 6262 & 84 & 1632 & 6262 \\
\hline 15 & 15624 & & & 15624 & & & 15624 \\
\hline 16 & 32072 & 194 & 5978 & 25900 & 194 & 5978 & 25900 \\
\hline 17 & 63014 & & & 63014 & & & 63014 \\
\hline 18 & 128746 & 512 & 23798 & 104436 & 512 & 23798 & 104436 \\
\hline 19 & 253588 & & & 253588 & & & 253588 \\
\hline 20 & 516346 & 1352 & 88302 & 426692 & 1352 & 88302 & 426692 \\
\hline 21 & 1019072 & & & 1019072 & & & 1019072 \\
\hline
\end{tabular}


Appendix

Table A1 - Subscript notation, response based labelling and associated form of the: (a) extensional stiffness matrix, [A]; (b), bending stiffness matrix, [D] and; (c) coupling stiffness matrix, $[\mathbf{B}]$. Note that all stiffness matrices have square symmetric form for balanced plain weave material. Note also that the $A_{I}$ and $D_{I}$ are used in place of $A_{S}$ and $\mathrm{D}_{\mathrm{S}}$ to denote isotropic stiffness relationships as defined in Eqs (14) and (15).

(a)

\begin{tabular}{ccc}
\hline $\begin{array}{c}\text { Subscript } \\
\text { notation } \\
(\text { ESDU, 1994) }\end{array}$ & Response-based labelling & Matrix form \\
\hline \hline \multirow{2}{*}{$\mathbf{A}_{\mathrm{S}}$} & Simple laminate & {$\left[\begin{array}{ccc}\mathrm{A}_{11} & \mathrm{~A}_{12} & 0 \\
\mathrm{~A}_{12} & \mathrm{~A}_{11} & 0 \\
0 & 0 & \mathrm{~A}_{66}\end{array}\right]$} \\
& Shear-Extension; & {$\left[\begin{array}{ccc}\mathrm{A}_{11} & \mathrm{~A}_{12} & \mathrm{~A}_{16} \\
\mathrm{~A}_{12} & \mathrm{~A}_{11} & -\mathrm{A}_{16} \\
\mathrm{~A}_{16} & -\mathrm{A}_{16} & \mathrm{~A}_{66}\end{array}\right]$} \\
\hline
\end{tabular}

(b)

\begin{tabular}{ccc}
\hline $\begin{array}{c}\text { Subscript } \\
\text { notation } \\
(\text { ESDU, 1994) }\end{array}$ & Response-based labelling & Matrix form \\
\hline \hline & Simple laminate & {$\left[\begin{array}{ccc}\mathrm{D}_{11} & \mathrm{D}_{12} & 0 \\
\mathrm{D}_{12} & \mathrm{D}_{11} & 0 \\
0 & 0 & \mathrm{D}_{66}\end{array}\right]$} \\
$\mathbf{D}_{\mathrm{S}}$ & Twisting-Bending; & {$\left[\begin{array}{ccc}\mathrm{D}_{11} & \mathrm{D}_{12} & \mathrm{D}_{16} \\
\mathrm{D}_{12} & \mathrm{D}_{11} & -\mathrm{D}_{16} \\
\mathrm{D}_{16} & -\mathrm{D}_{16} & \mathrm{D}_{66}\end{array}\right]$} \\
$\mathbf{D}_{\mathrm{F}}$ & $\underline{T-B}$
\end{tabular}


(c)

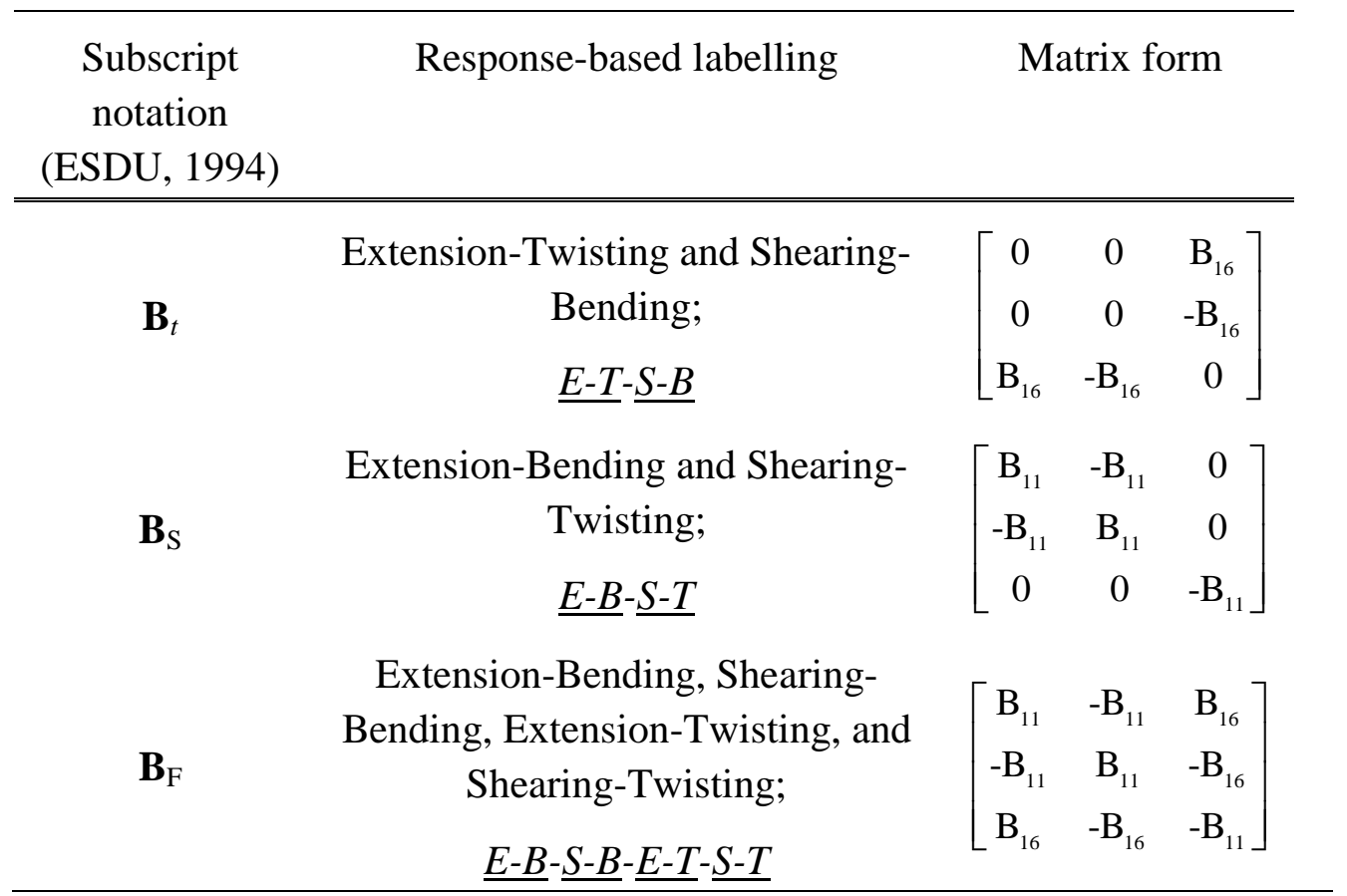


Table A2 - Abridged listing for Simple laminates $\left(\mathbf{A}_{S} \mathbf{B}_{0} \mathbf{D}_{S}\right)$, corresponding to $\beta=0$ and $\alpha=\beta+\pi / 4$, for increasing buckling strength of the infinitely long plate with simply supported edges. Note that for ply number groupings $n=4$ and above, the maximum buckling strength arises from stacking sequences of the form $\left[\alpha_{n}\right]_{\mathrm{T}}$, corresponding to lamination parameter $\xi_{2}=\xi_{8}=-1$ with $\mathrm{k}_{\mathrm{x}}=5.06$ and corresponding buckling halfwavelength $\lambda=b$.

\begin{tabular}{|c|c|c|c|c|}
\hline$n$ & Stacking Sequences & $\xi_{2}$ & $\xi_{10}$ & $\mathrm{k}_{\mathrm{x}}$ \\
\hline 2 & {$[\alpha / \alpha]_{\mathrm{T}}$} & -1.00 & -1.00 & 5.06 \\
\hline 3 & {$[\alpha / \beta / \alpha]_{\mathrm{T}}$} & -0.33 & -0.93 & 4.98 \\
\hline 3 & {$\left[\alpha_{3}\right]_{\mathrm{T}}$} & -1.00 & -1.00 & 5.06 \\
\hline 4 & {$\left[\alpha / \beta_{2} / \alpha\right]_{\mathrm{T}}$} & 0.00 & -0.75 & 4.80 \\
\hline$:$ & & & & \\
\hline $\begin{array}{l}5 \\
:\end{array}$ & {$\left[\alpha / \beta_{3} / \alpha\right]_{\mathrm{T}}$} & 0.20 & -0.57 & 4.60 \\
\hline 6 & {$\left[\alpha / \beta_{4} / \alpha\right]_{\mathrm{T}}$} & 0.33 & -0.41 & 4.43 \\
\hline $\begin{array}{l}: \\
7\end{array}$ & {$\left[\alpha / \beta_{3} / \alpha_{2} / \beta\right]_{\mathrm{T}}$} & 0.14 & 0.00 & 4.00 \\
\hline : & & & & \\
\hline 8 & {$\left[\alpha / \beta_{2} / \alpha / \beta / \alpha_{2} / \beta\right]_{\mathrm{T}}$} & 0.00 & 0.00 & 4.00 \\
\hline$\dot{9}$ & {$\left[\alpha / \beta_{4} / \alpha / \beta / \alpha / \beta\right]_{\mathrm{T}}$} & 0.33 & 0.14 & 3.86 \\
\hline 10 & {$\left[\alpha / \beta_{4} / \alpha_{3} / \beta_{2}\right]_{\mathrm{T}}$} & 0.20 & 0.30 & 3.69 \\
\hline$:$ & & & & \\
\hline $\begin{array}{c}11 \\
.\end{array}$ & {$\left[\alpha / \beta_{6} / \alpha_{2} / \beta_{2}\right]_{\mathrm{T}}$} & 0.46 & 0.31 & 3.68 \\
\hline 12 & {$\left[\alpha / \beta_{5} / \alpha_{2} / \beta / \alpha / \beta_{2}\right]_{\mathrm{T}}$} & 0.33 & 0.37 & 3.61 \\
\hline 13 & {$\left[\alpha / \beta_{6} / \alpha_{3} / \beta_{3}\right]_{\mathrm{T}}$} & 0.39 & 0.45 & 3.52 \\
\hline $\begin{array}{c}: \\
14\end{array}$ & $\left\lceil\alpha / \beta_{\sigma} / \alpha / \beta / \alpha\right.$ & 0.43 & 0.46 & 3.51 \\
\hline $\begin{array}{c}14 \\
:\end{array}$ & {$\left[\alpha / p_{6} / \alpha / p / \alpha\right.$} & 0.43 & 0.40 & 5.01 \\
\hline 15 & {$\left[\alpha / \beta_{7} / \alpha_{2} / \beta / \alpha / \beta_{3}\right]_{\mathrm{T}}$} & 0.47 & 0.50 & 3.47 \\
\hline 16 & {$\left[\alpha / \beta_{8} / \alpha_{3} / \beta_{4}\right]_{\mathrm{T}}$} & 0.50 & 0.54 & 3.42 \\
\hline 17 & {$\left[\alpha / \beta_{8} / \alpha / \beta / \alpha_{2} / \beta_{4}\right]_{\mathrm{T}}$} & 0.53 & 0.56 & 3.41 \\
\hline
\end{tabular}


1

2

3

4

5

6

7

8

9

10

11

12

13

14

15

16

17

18

19

20

21

22

23

24

25

26

27

28

29

30

31

32

33

34

35

36

37

38

39

40

41

42

43

44

45

46

47

48

49

50

51

52

53

54

55

56

57

58

59

60

61

62

63

64

65

$$
\begin{array}{ccccc}
18 & {\left[\alpha / \beta_{9} / \alpha_{2} / \beta / \alpha / \beta_{4}\right]_{\mathrm{T}}} & 0.56 & 0.58 & 3.38 \\
: & & & & \\
19 & {\left[\alpha / \beta_{10} / \alpha_{3} / \beta_{5}\right]_{\mathrm{T}}} & 0.58 & 0.61 & 3.35 \\
: & & & & \\
20 & {\left[\alpha / \beta_{10} / \alpha / \beta / \alpha_{2} / \beta_{5}\right]_{\mathrm{T}}} & 0.60 & 0.62 & 3.34 \\
: & & & & \\
21 & {\left[\alpha / \beta_{10} / \alpha_{4} / \beta_{6}\right]_{\mathrm{T}}} & 0.52 & 0.66 & 3.30 \\
\hline
\end{array}
$$


Table A3 - Abridged listing for Extension-Twisting and Shearing-Bending coupled laminates $\left(\mathbf{A}_{I} \mathbf{B}_{t} \mathbf{D}_{I}\right)$, corresponding to $\beta=\pi / 8$ and $\alpha=\beta+\pi / 4$, for increasing coupling magnitude, $\xi_{8}$, and corresponding buckling factor $\mathrm{k}_{\mathrm{x}}$ for the infinitely long plate with simply supported edges. For ply number groupings above $n=6$, the maximum coupling magnitude $\left(\xi_{8}=1\right.$ and $\left.\mathrm{k}_{\mathrm{x}}=3.40\right)$ arises from stacking sequences of the form $\left[\alpha_{n / 2} / \beta_{n / 2}\right]_{\mathrm{T}}$, and are therefore omitted.

\begin{tabular}{|c|c|c|c|}
\hline$n$ & Stacking Sequences & $\xi_{8}$ & $\mathrm{k}_{\mathrm{x}}$ \\
\hline 2 & {$[\alpha / \beta]_{\mathrm{T}}$} & 1.00 & 3.40 \\
\hline 4 & {$[\alpha / \beta / \alpha / \beta]_{\mathrm{T}}$} & 0.50 & 3.85 \\
\hline 4 & {$\left[\alpha_{2} / \beta_{2}\right]_{\mathrm{T}}$} & 1.00 & 3.40 \\
\hline 6 & {$\left[\alpha / \beta_{2} / \alpha_{2} / \beta\right]_{\mathrm{T}}$} & 0.11 & 3.99 \\
\hline : & $:$ & : & \\
\hline 6 & {$\left[\alpha_{3} / \beta_{3}\right]_{\mathrm{T}}$} & 1 & 3.40 \\
\hline 8 & {$\left[\alpha / \beta_{3} / \alpha_{3} / \beta\right]_{\mathrm{T}}$} & -0.13 & 3.99 \\
\hline : & $:$ & $:$ & \\
\hline 10 & {$\left[\alpha / \beta_{2} / \alpha_{2} / \beta_{2} / \alpha_{2} / \beta\right]_{\mathrm{T}}$} & 0.04 & 3.99 \\
\hline$:$ & $:$ & $:$ & \\
\hline 12 & {$\left[\alpha / \beta_{2} / \alpha_{2} / \beta / \alpha / \beta_{2} / \alpha_{2} / \beta\right]_{\mathrm{T}}$} & 0.06 & 3.99 \\
\hline$:$ & $:$ & $:$ & \\
\hline 14 & {$\left[\alpha / \beta_{2} / \alpha / \beta / \alpha_{2} / \beta / \alpha / \beta / \alpha / \beta_{2} / \alpha\right]_{\mathrm{T}}$} & 0.02 & 4.00 \\
\hline$:$ & $:$ & $:$ & \\
\hline 16 & {$\left[\alpha / \beta_{2} / \alpha / \beta / \alpha_{3} / \beta_{3} / \alpha / \beta / \alpha_{2} / \beta\right]_{\mathrm{T}}$} & 0.03 & 4.00 \\
\hline : & $:$ & $:$ & \\
\hline 18 & {$\left[\alpha / \beta_{3} / \alpha_{4} / \beta_{2} / \alpha / \beta / \alpha / \beta_{2} / \alpha / \beta / \alpha\right]_{\mathrm{T}}$} & 0.01 & 4.00 \\
\hline : & $:$ & $:$ & \\
\hline 20 & {$\left[\alpha / \beta_{3} / \alpha_{2} / \beta / \alpha_{4} / \beta_{3} / \alpha / \beta_{3} / \alpha_{2}\right]_{\mathrm{T}}$} & 0.02 & 4.00 \\
\hline : & : & : & \\
\hline
\end{tabular}

